UNITED STATES DEPARTMENT OF THE INTERIOR

GEOLOGICAL SURVEY

DIFFERENTIAL-GROUND-MOTION ARRAY AT HOLLISTER MUNICIPAL AIRPORT, CALIFORNIA

by

G. N. Bycroft

OPEN-FILE REPORT

$83--327$

This report is preliminary and has not been reviewed for conformity with U.S. Geological Survey editorial standards.

Any use of trade names is for descriptive purposes only and does not imply endorsement by the USGS. 


\title{
DIFFERENTIAL-GROUND-MOTION ARRAY AT HOLLISTER MUNICIPAL AIRPORT, CALIFORNIA
}

\author{
G. N. Bycroft \\ U.S. Geological Survey \\ Menlo Park, California 94025
}

ABSTRACT

This report describes the differential array of seismometers recently installed at the Hollister, California, Municipal Airport. Suci an array of relatively closely spaced seismometers has already been installed in El Centro and provided useful information for both engineering and seismological applications from the 1979 Imperial Valley earthquake. Differential ground motions, principally due to horizontally propagating surface waves, are important in determining the stresses in such extended structures as large mat foundations for nuclear power stations, dams, bridges and pipelines. Further, analyses of the records of the 1979 Imperial Valley earthquake from the differential array have demonstrated the utility of short-baseline array data in tracking the progress of the rupture wave front of an earthquake. 


\section{INTRODUCTION}

Aseismic desian has generally assumed that all points on the ground move in unison with the free-fiels motion over a region that is larger than the foundation of the structure. This assumption is based on the notion that seismic waves are substantially propagated in high-wave-velocity basement rock and transmitted vertically to the region of interest through lower velocity layers. However, surface waves and scattered waves propagating horizontally through surface layers may have wavelengths along the surface comparable to the dimensions of a larqe structure (Luco, 1969; Trifunac, 1972; Wong and Trifunac, 1974; Bycroft, 1980). The foundation of the structure would then undergo differential motions that would cause additional strains to be superimposed on those due to inertial loajing. Thus, adjacent bridje piers, for examole, would move relative to each other and cause substantial stresses in the piers and the bridge decking. Structures built on spread footings, dams, and pipelines would be similarly affected. A large relatively rigid raft foundation, such as may be used for a nuclear power station, would move less than the free-field motion (Bycroft, 1980), and so the input to structures on such a foundation would then be attenuated; the input motion to such structures would differ from the free-fiels motion.

To study such motion, differential ground motions must be measured, and methods of utilizing this information in aseismic design must ve developed. The measurement of free-field ground motion is relatively straightforward in that no spatial parameter is involved. For differential ground motions, however, surface waves may propagate at wavelengths comparable to the size of the foundation, and so a spatial array of instruments is needed. If expense were no consideration, a fully three-dimensional array consisting of many instruments could be built. Initially, it would appear more advantageous to divide these instruments among several simpler arrays in different suitable regions of high seismicity in amolitude and occurrence. To detect surface waves of significant amplitude, regions of large contrast in wave velocity between the surface and underlying layers must be selected. The upper layer should be of as low a velocity as possible, so that the wavelengths are as short as possible. Furthermore, the selected region should be flat, homogeneous, and secure; power should be readily available; and the regional velocity profile should be known. Further, the instrumentation should be digital with common time on all channels and be trigqered from a common trigger. In order to account for the angle of arrival of waves, the array should be two-dimensional. The array should incorporate as much redundancy as possible to allow for channel failure. The differential motion between any two points is a function of their difference apart. Thus, the difference in motion between points at varying distances apart should be measured. If $n$ instruments are to be used, there are $n(n-1) / 2$ pairs of points whose distances apart may be arranged to be different. The instruments should be placed so that these distances increase reasonably uniformly from smallest to largest, assuming that the region is uniform over an area somewhat larger than that of the array.

\section{HOLLISTER DIFFERENTIAL-GROUND-MOTION ARRAY}

A differential ground motion array has been installed at the Hollister Municioal Airport, California. This region is reasonably secure and has power 
available at the west end. This array is intended to be used for determining differential motions between points. The array should also provide data useful for seismological investigations such as studying the rupture process of an earthquake, the relative importance of surface waves and body waves, their a $\rho-$ parent velocities and wavelengths along the earth's surface, and their angles of incidence.

Fiqure 1 shows the location of the array in relation to the airport runways and to the San Andreas fault. One leg of the array runs parallel to and on the southern side of the E-W runway for a distance of 2000 feet and the second leg runs along a boundary of an orchard at an angle of $3 y^{\circ}$ for a distance of 1000 feet. The vertex of the array is at longitude $121^{\prime} 26^{\prime} 45^{\prime \prime}$ and latitude $36^{\circ} 53^{\prime} 17^{\prime \prime}$. Fiqure 2 shows the geologic structure from two boring logs made at Hollister City Hall approximately two miles from the airport by woodwardLundaren Associates. Fiqure 3 shows the configuration of the array. Tnis arrangement gives a satisfactory spread of distances between the various instruments, is two-dimensional and has two instruments close enough to each other to provide a certain redundancy at each of the three corners. The sensors are Kinemetrics FBA3 and the recorders are KinemetricS DSA-1.

The FBA-3 is a triaxial force balance accelerometer. It is packaged in a cast aluminum base and cover, and sealed to prevent the entrance of moisture and dirt. The three accelerometers are orthogonally mounted on an internal deck plate. Provision is made for applying electrical commands which result in outputing the damped and undamped response of the three accelerometers.

The nominal specifications are:

$\begin{array}{ll}\text { Full scale range } & \pm 1 \mathrm{~g} \\ \text { Outout } & \pm 2.5 \text { volts } \mathrm{DC} \\ \text { Natural frequency } & 50 \mathrm{~Hz} \\ \text { Damping } & .70 \mathrm{critical} \\ \text { Supply voltages } & +-12 \mathrm{VDC} \\ \text { Temperature effects } & \pm 2 \text { full scale from } 0^{\circ} \text { to } 150^{\circ} \mathrm{F} \\ \text { Output } & \pm 2.5 \text { volts full scale } \\ \text { Calibration } & \text { Provision for Jamping and natural } \\ & \text { frequency commanss }\end{array}$

The DSA-1 is a triaxial strong-motion accelerograph which converts the analog outputs of the FBA-3 accelerometers into proportional digital values and records the digital data on a four-track magnetic tape cassette. The instrument includes a pre-event memory. The instrumentation is triggered by an SMA-1 accelerometer located in the recorder building.

When the seismic trigger senses the initial ground motion, it turns power on to the tape drive motor and the DSA-1 is fully actuated in less than 1.1 second. The DSA-1 operates as long as the trigger detects the earthquake, 
plus an additional 10 seconds (adjustable) after the motion drops below the trigger threshold. The radio time signal WWVB is also recorded.

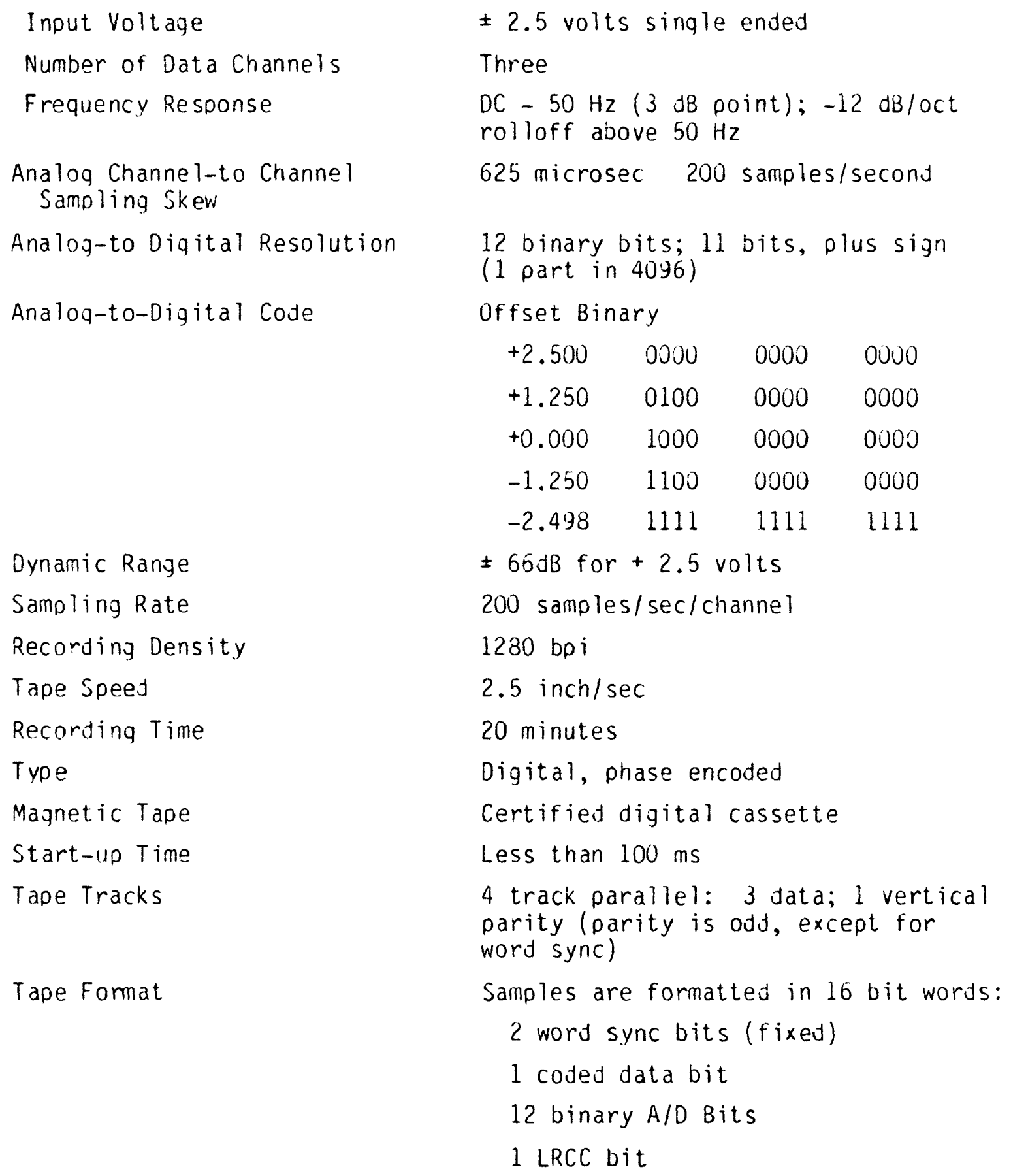


Coded Data

Pre-event Memory

Voltage

Standby Current

Recording Current
(Each 64 th sample period all zero's are recorded on all four tracks for synchronization.)

Track 1: instrument serial number and samoling rate.

Track 2: for internal 2 PPS timing

Track 3: for WWVB

Track 4: parity

2.56 secs.

+12 and -12 VDC

$0.15 \mathrm{ma}+12 \mathrm{~V}$

300 na from +12 VDC (nominal)

300 ma from -12 VDC (nominal)

The recorders are housed in an air-conditioned fiberglass structure located at the west end of the array. The sensors are placed on concrete pads shown in Fig. 4 and covered by fiberglass housings.

The array recorded the Morgan $\mathrm{Hill}$ earthquake of April 24, 1984 at stations

$1,3,4,5$. Stations 2 and 6 malfunctioned. The accelerations, velocities and displacements are shown on payes 12 to 44 .

\section{REFERENCES CITED}

Bycroft, G.N., 1980, Soil foundation interaction and differential ground motions: Journal of Earthquake Engineering and Structural Dynamics, v. 8 , no. 5, p. 397-404.

Hansen, W.R., Weiss, R.B., Idress, I.M., and Cluff, L.S., 1973, Geotechnical data compilation for selected strong-motion sites: Oakland, Calif., Woodward-Lundgren Associates report, $411 \rho$.

Luco, J.E., 1969, Dynamic interaction of a shear wall with the soil: American Society of Civil Engineers Proceedings, Engineering Mechanics Division Journal, v. 95, no. EM2, p. 333-346.

Trifunac, M.D., 1972, Interaction of a shear wall with the soil for incident plane SH waves: Seismological Society of America Bulletin, v. 62, no. 1 , ค. 63-83.

Wong, H.L., and Trifunac, M.D., 1974, Interaction of a shear wall with the soil for incident plane SH waves: Elliptical rigid foundation: Seismological Society of America Bulletin, v. 64, no. 6, p. 1825-1842. 


\section{FIGURE CAPTIONS}

Fiqure 1-- Location of the array.

Fiqure 2-- Geological structure.

Figure 3-- Array conf iguration.

Fiqure 4-- Concrete pad for sensor. 


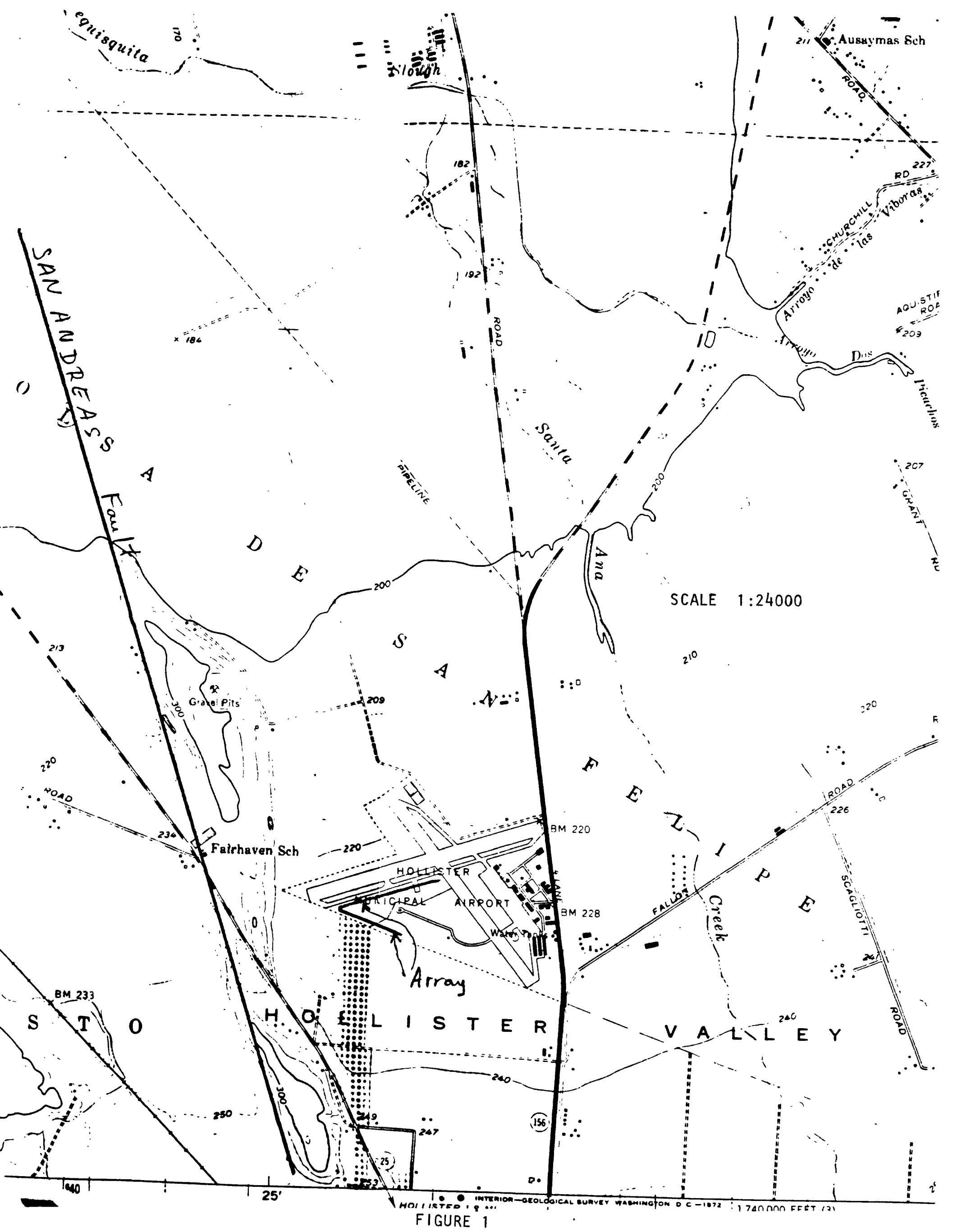



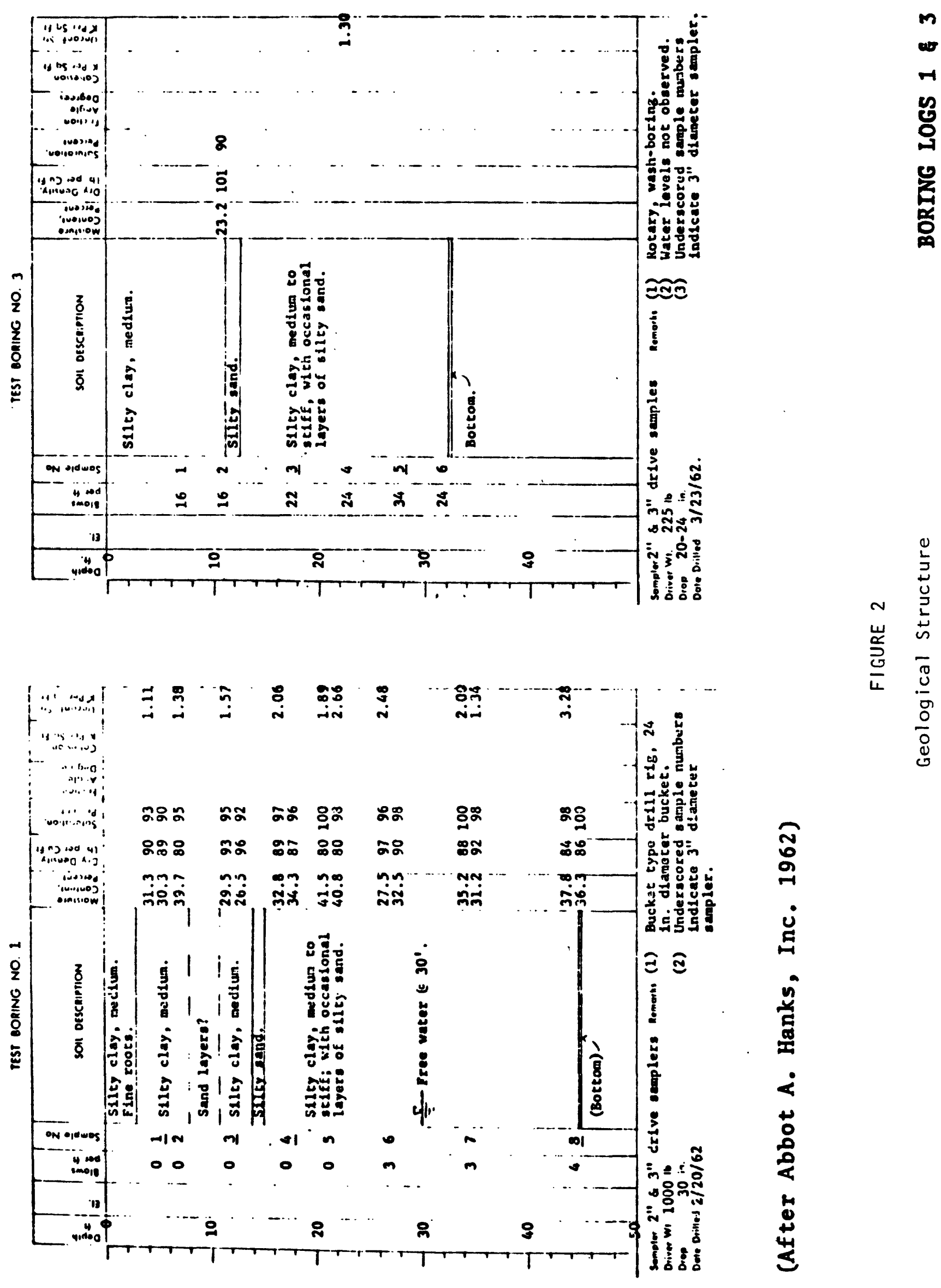


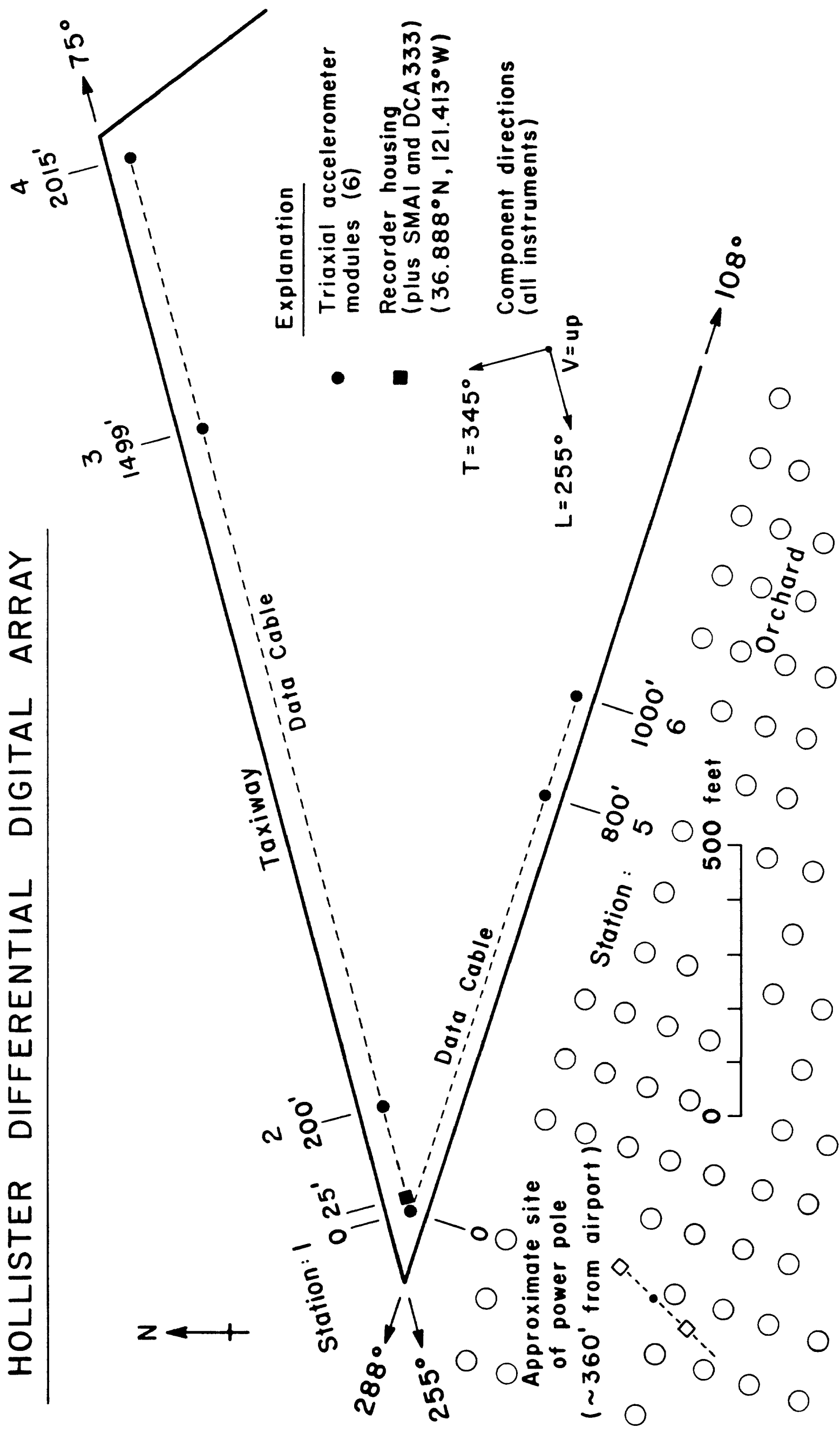



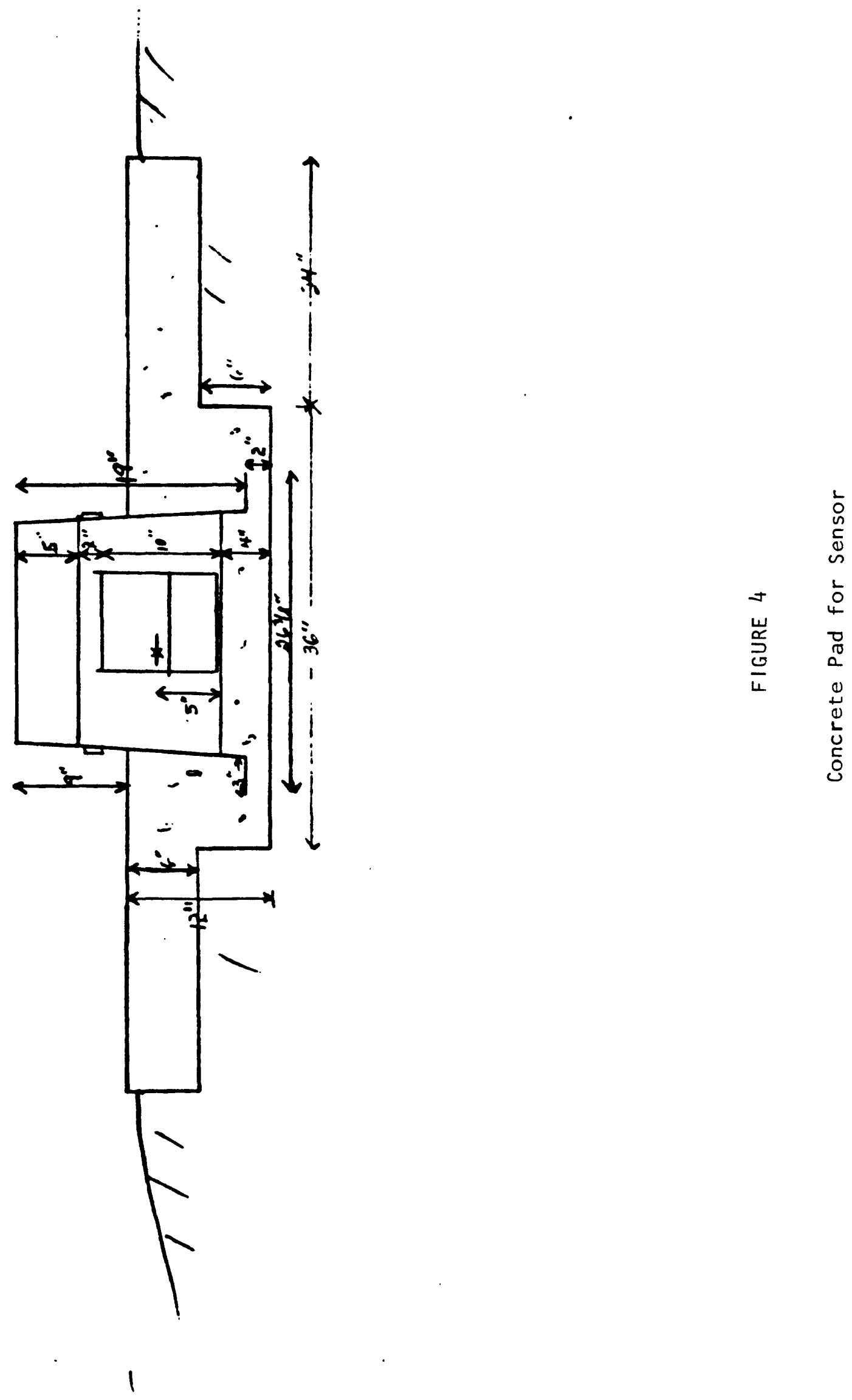


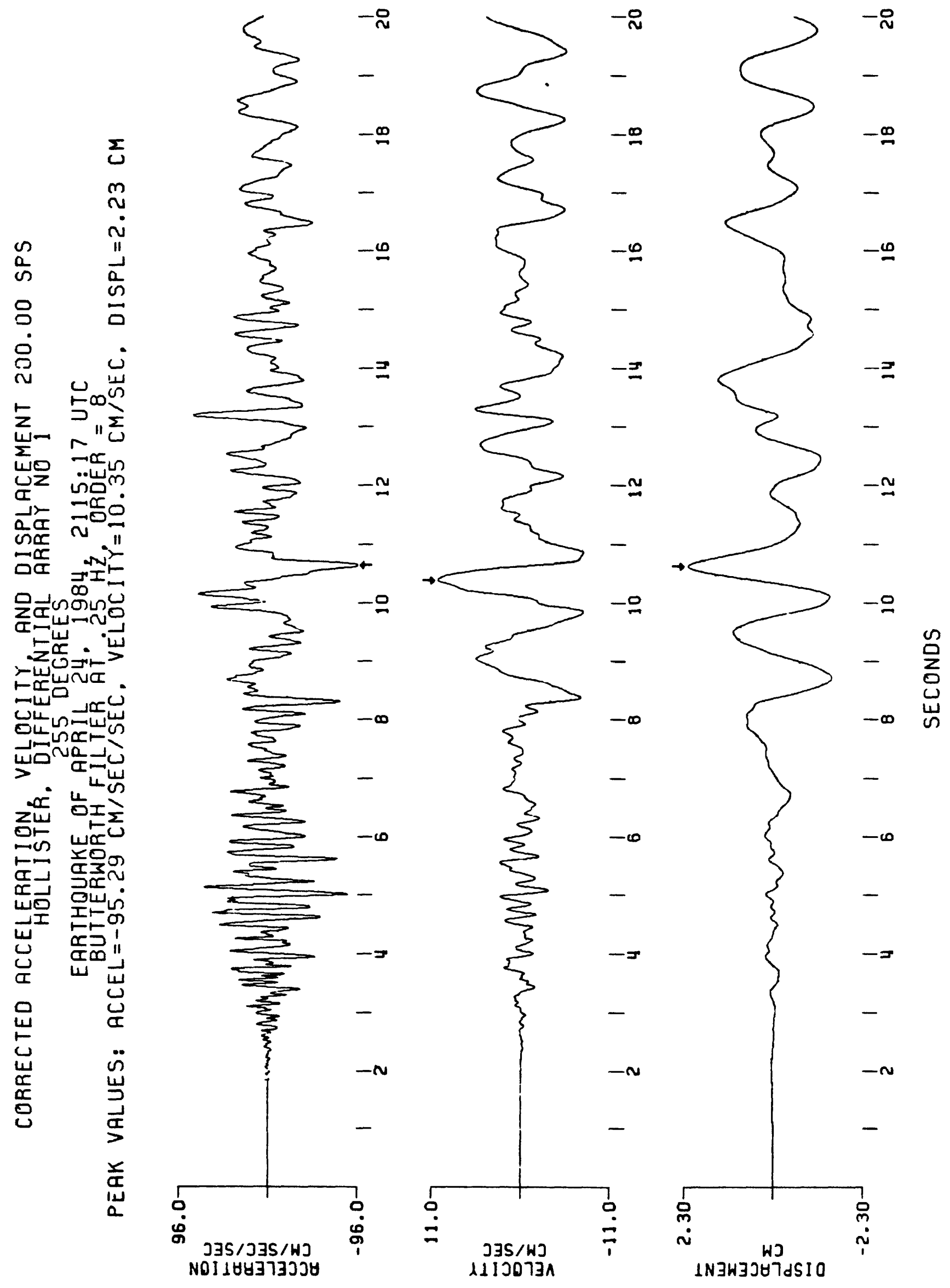




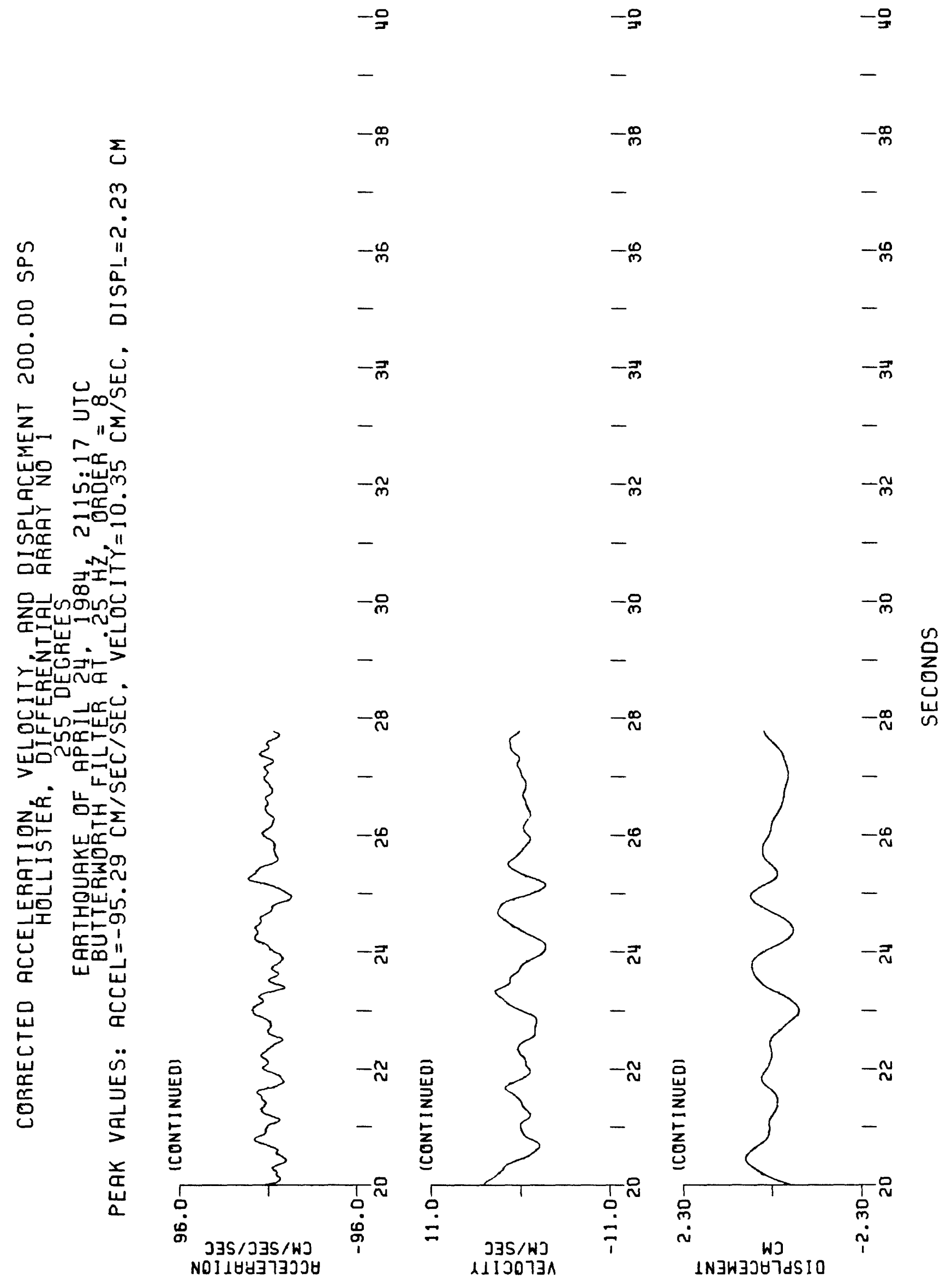




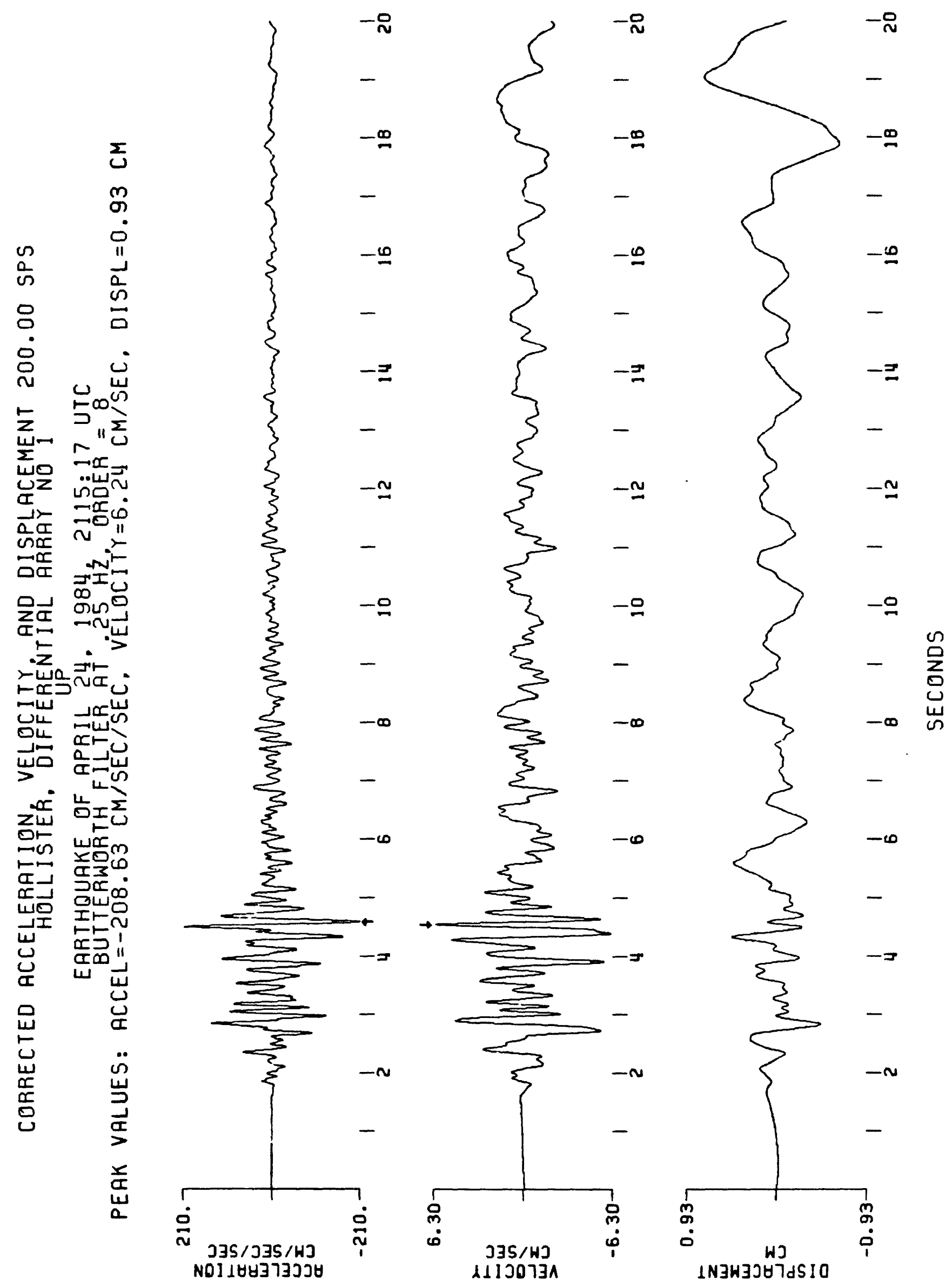




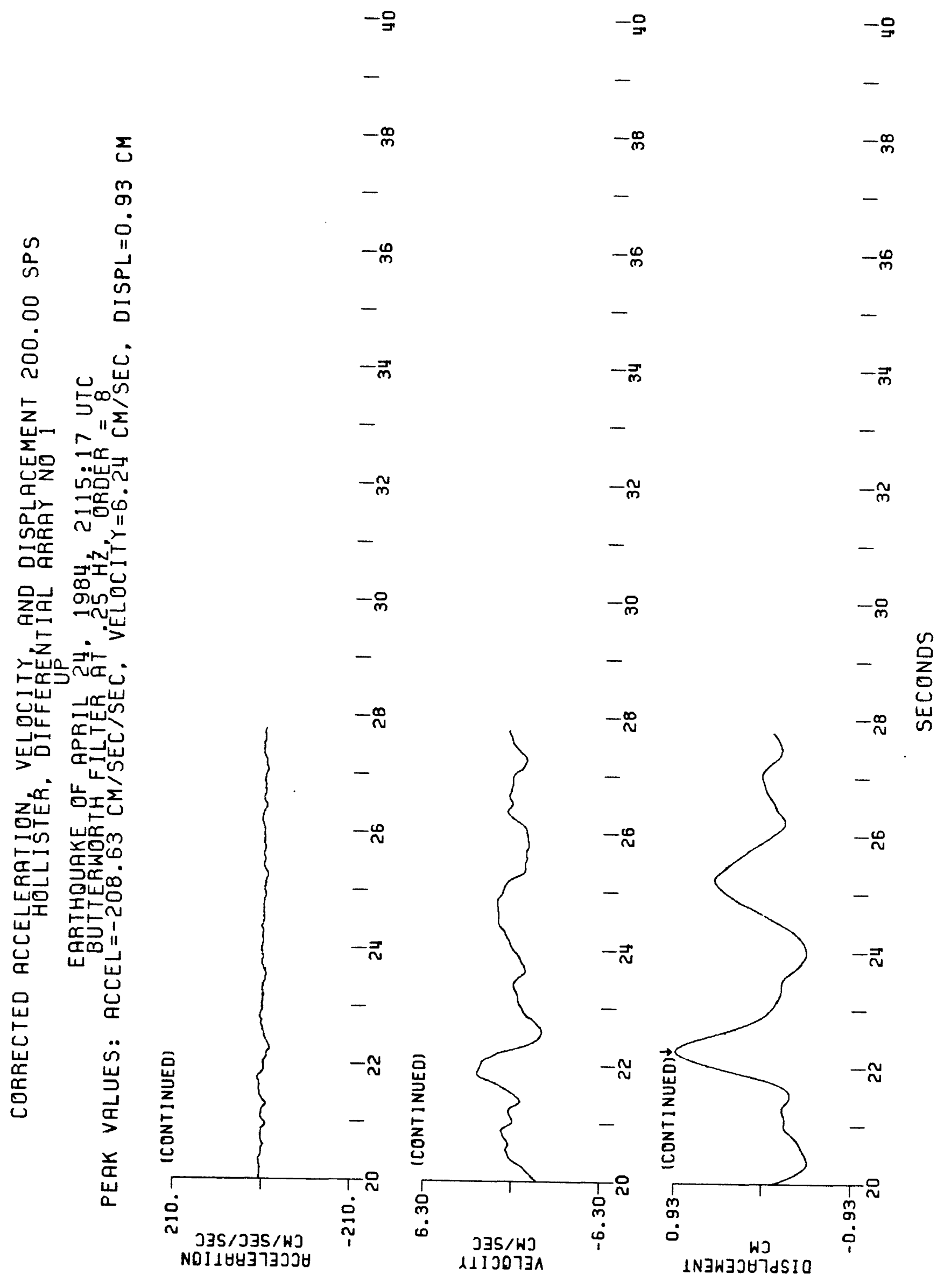




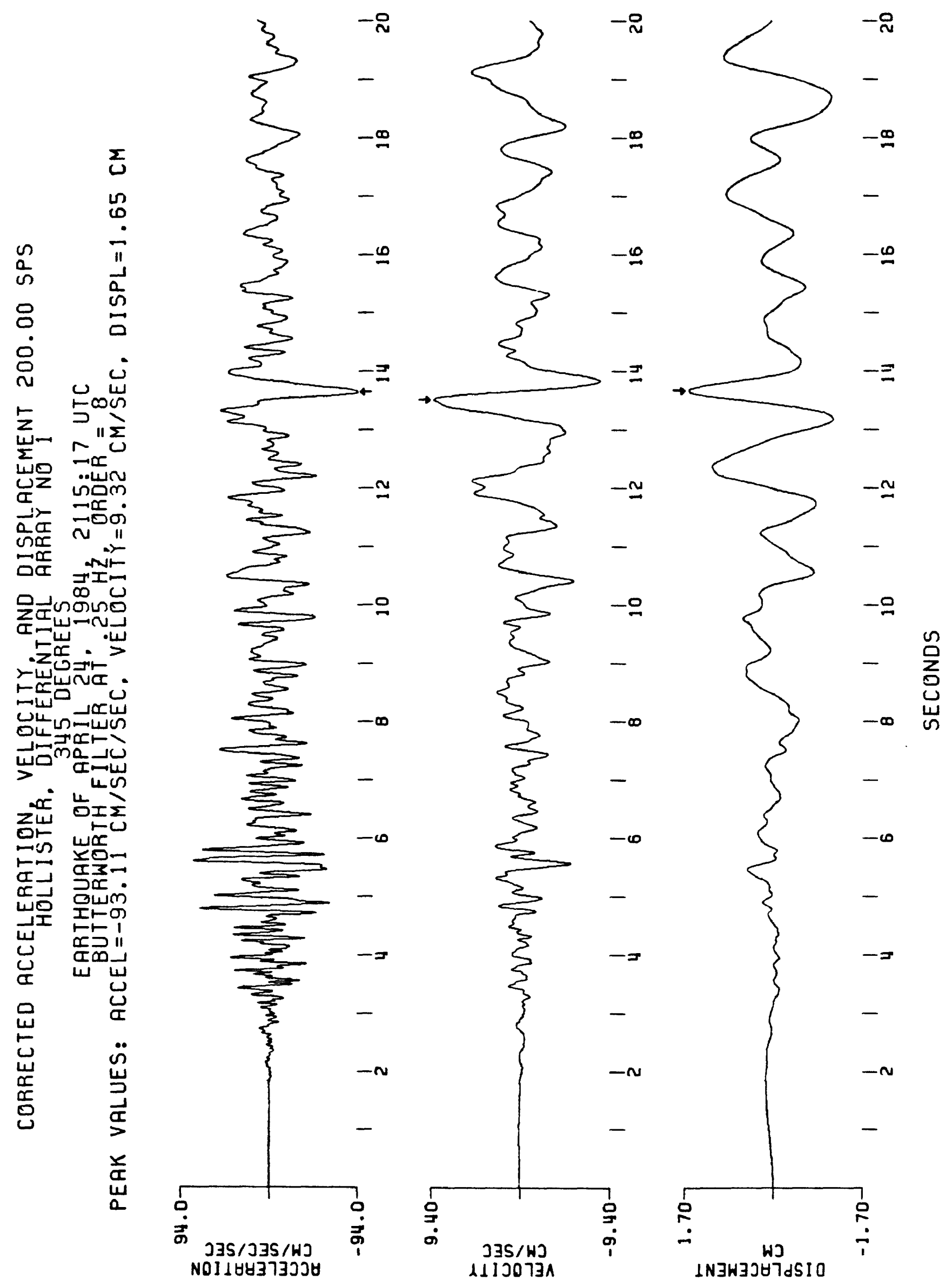




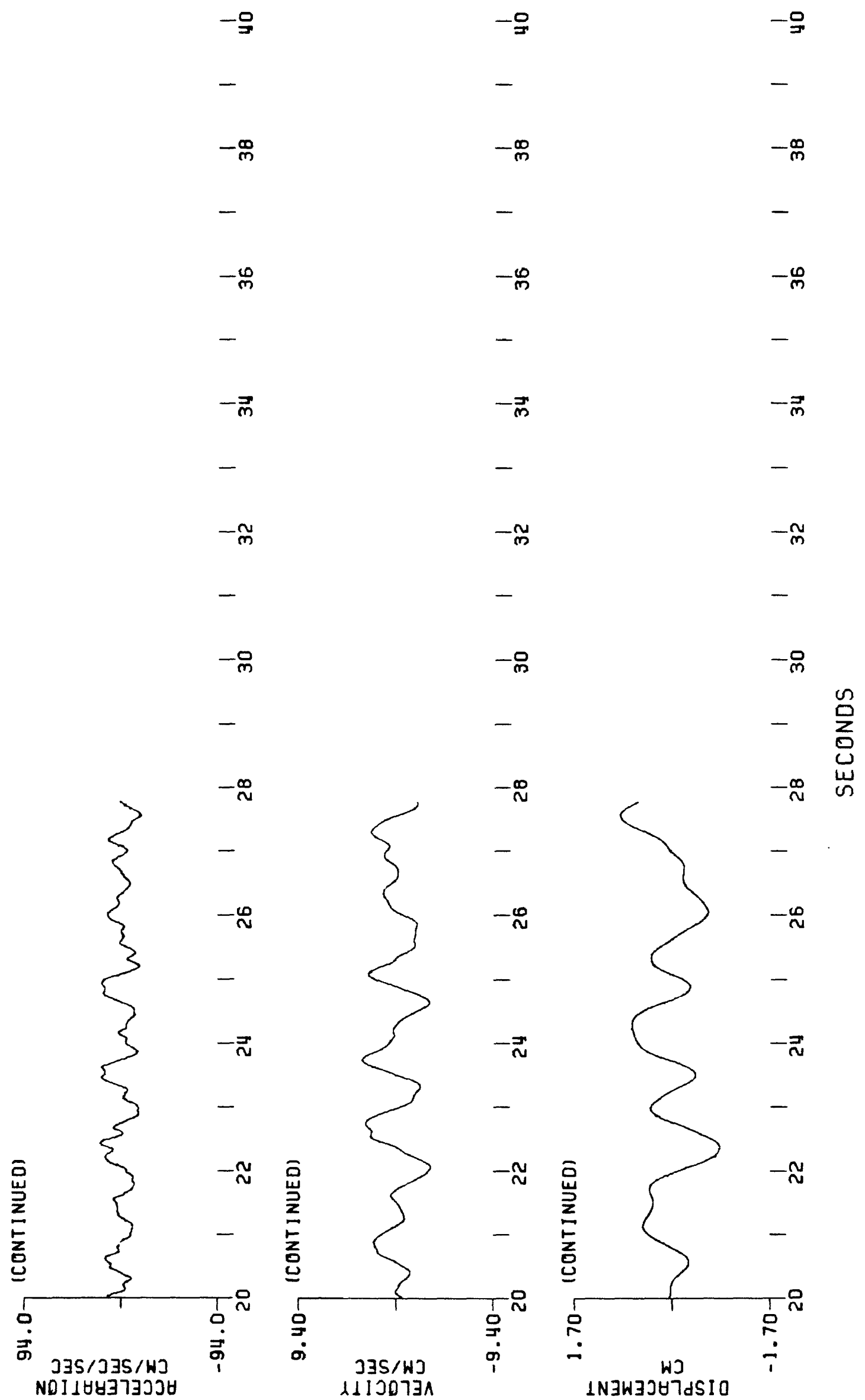

zămô์

() 


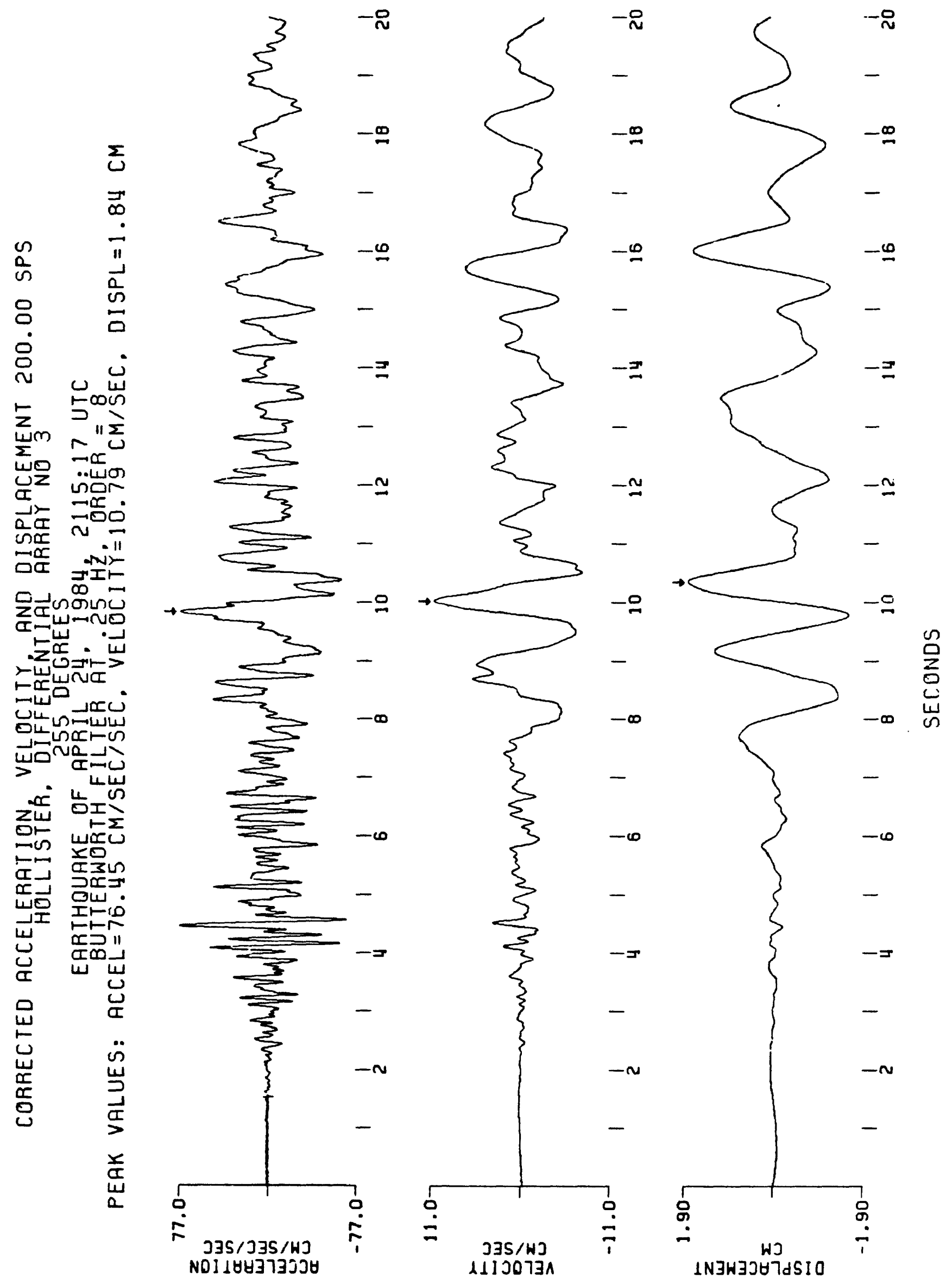




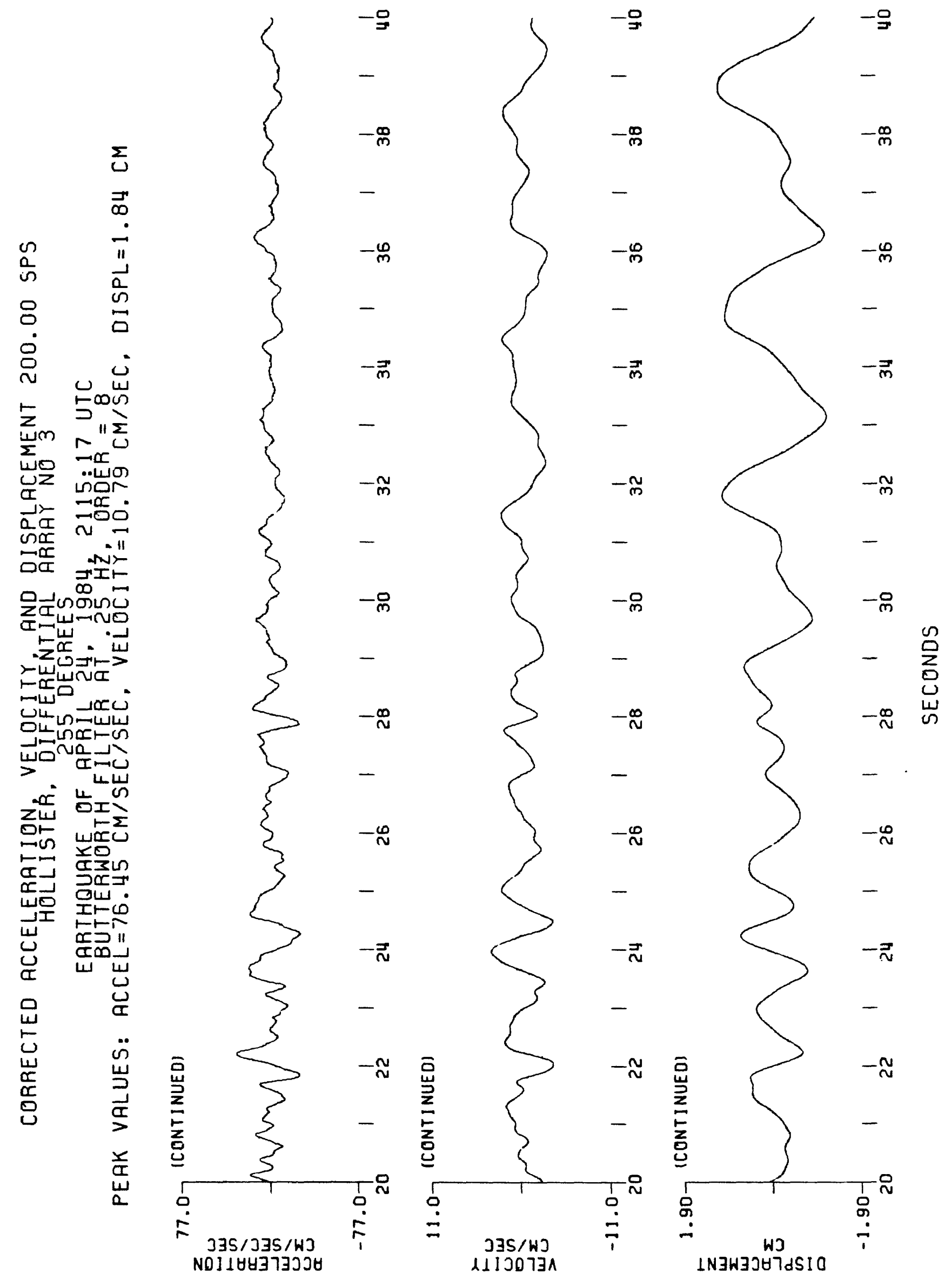




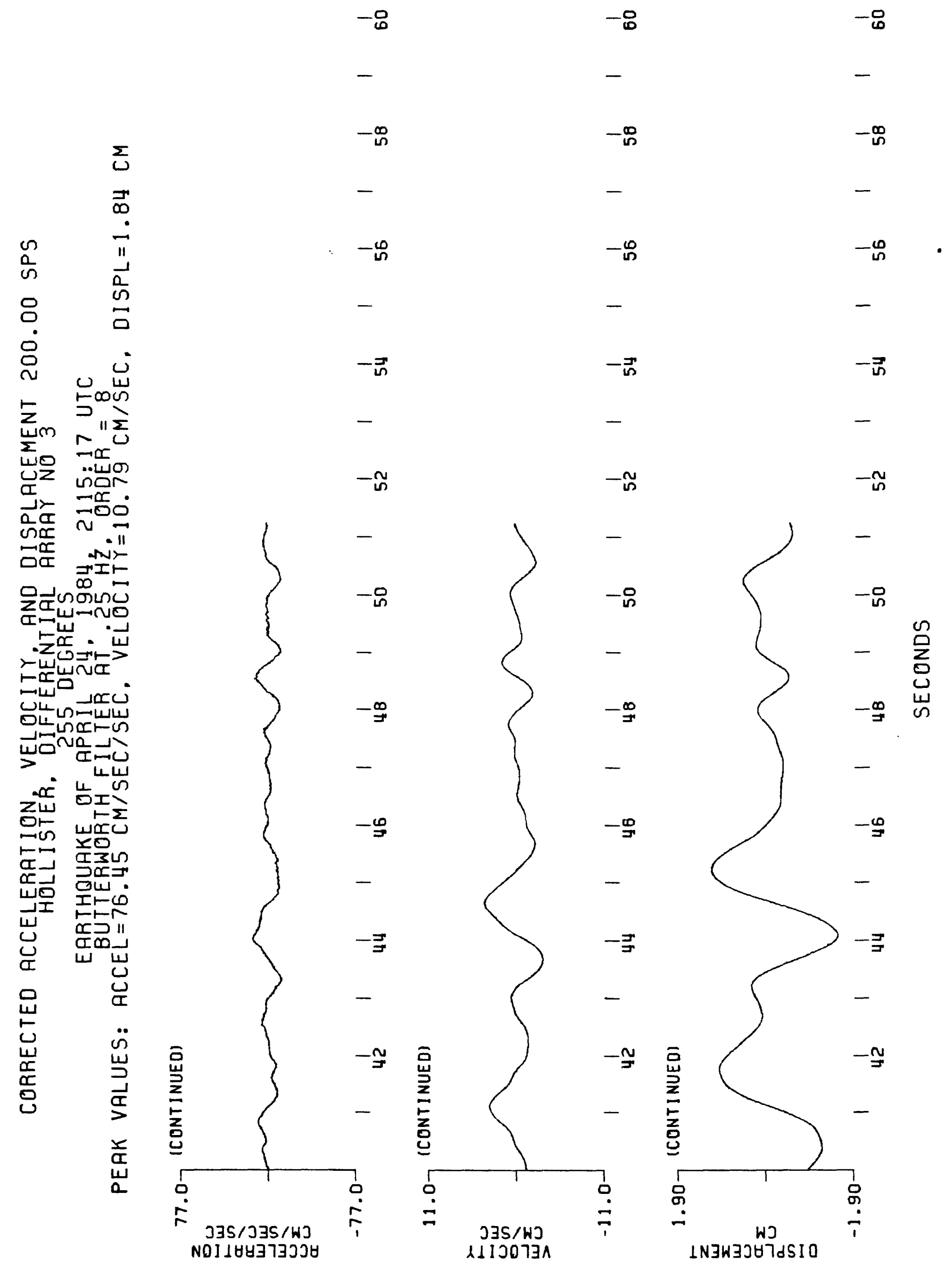




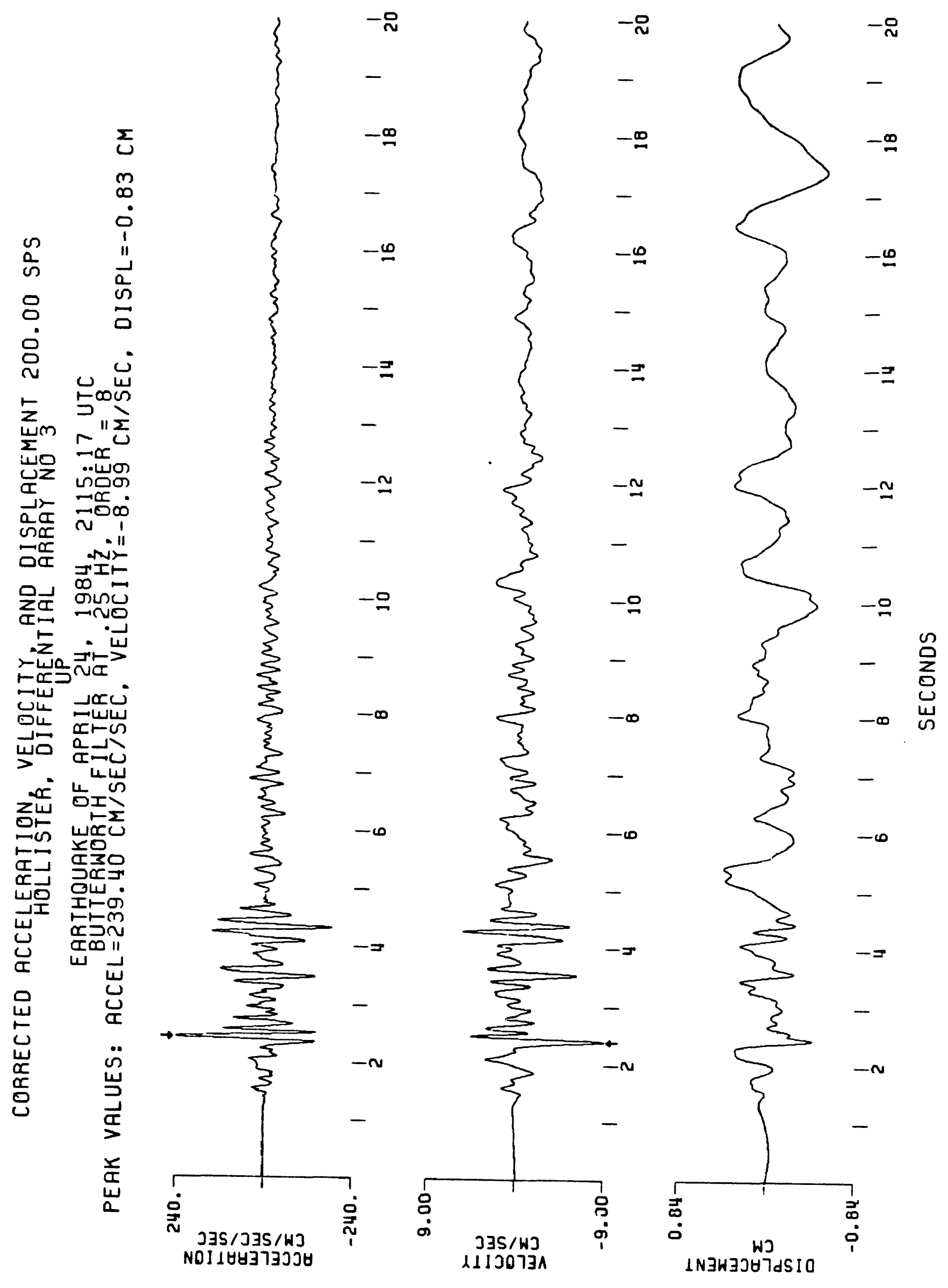




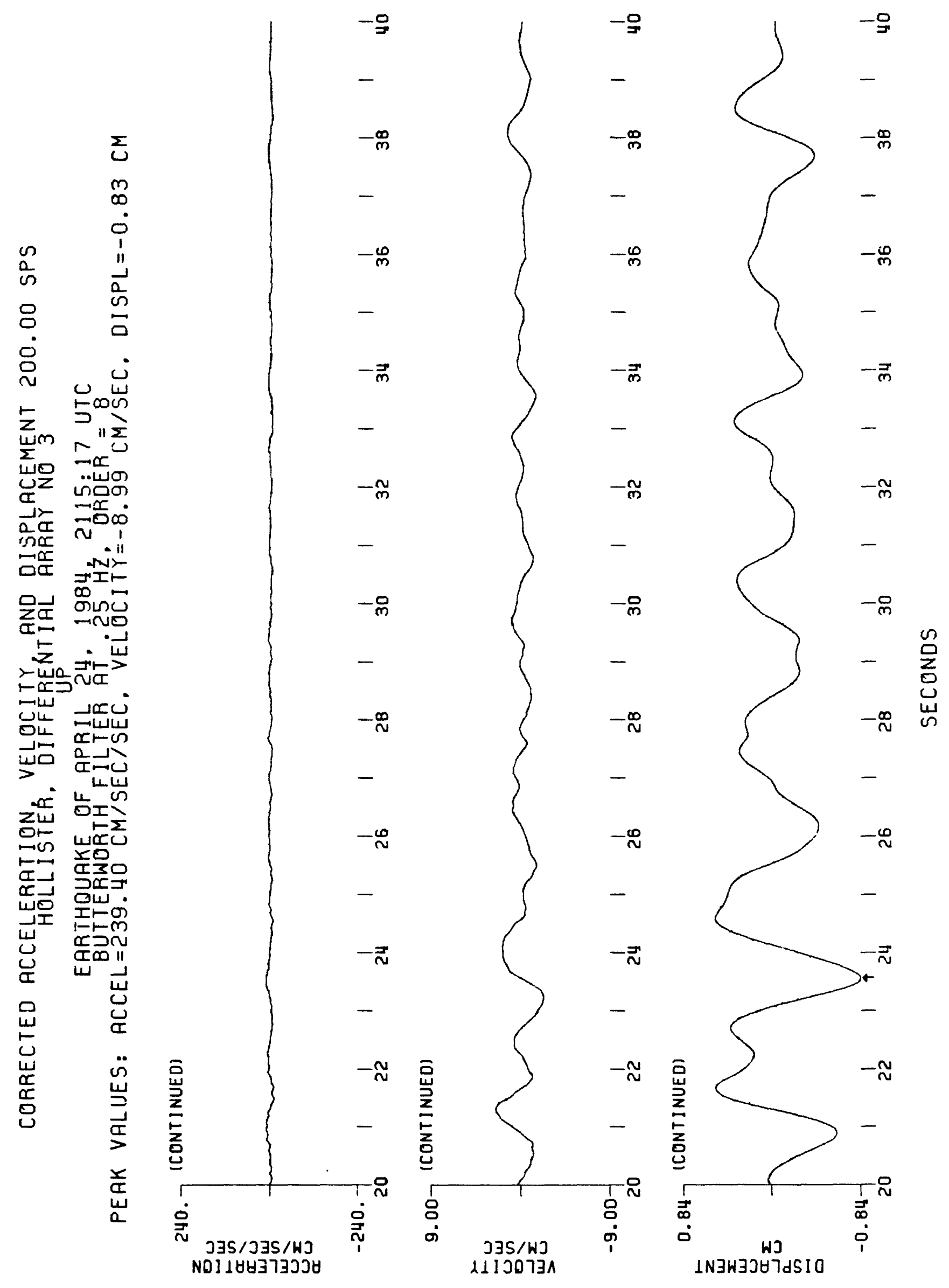


- 0

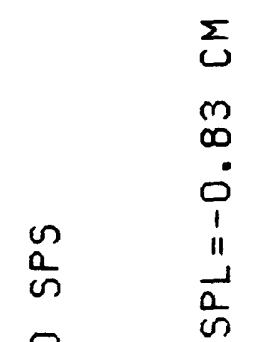

ט

$\leftarrow \quad 5 \infty$

$\sum_{u m}{ }_{11}$

$\sum^{\infty} \sim c$

wo 뻬

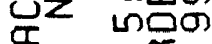

1)

ă $\vec{\sim}$

ज佂

娄 añ

0

리 बiñ

व曰

-z

>யn

㟧 -

பال

ol cron

шص 品元

$>$ แ山

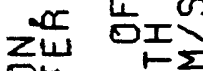

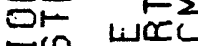

包 上o

떠 똥옹

몀 밍

님ㄷㅁ

$\vec{u}$

U

Itw

凹 बळ॥

山 ш

니 U

5

㠅 陆

$\frac{1}{0}$

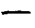

-

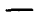

$-\infty$

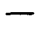

- ज्ञ

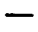

- in

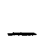

一온

-

$-\infty$

-

$-\mathscr{G}$

-

$-3$

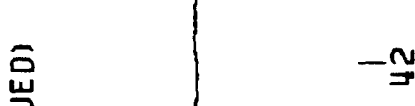

-
$-8$

$-9$

一曾

-

-

一

一䍃

-

- in
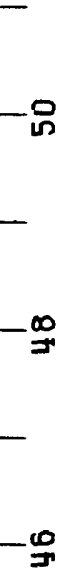

一
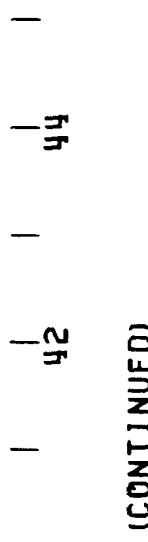

品 ว35/J3S/W NQ11 $4837353 \forall$
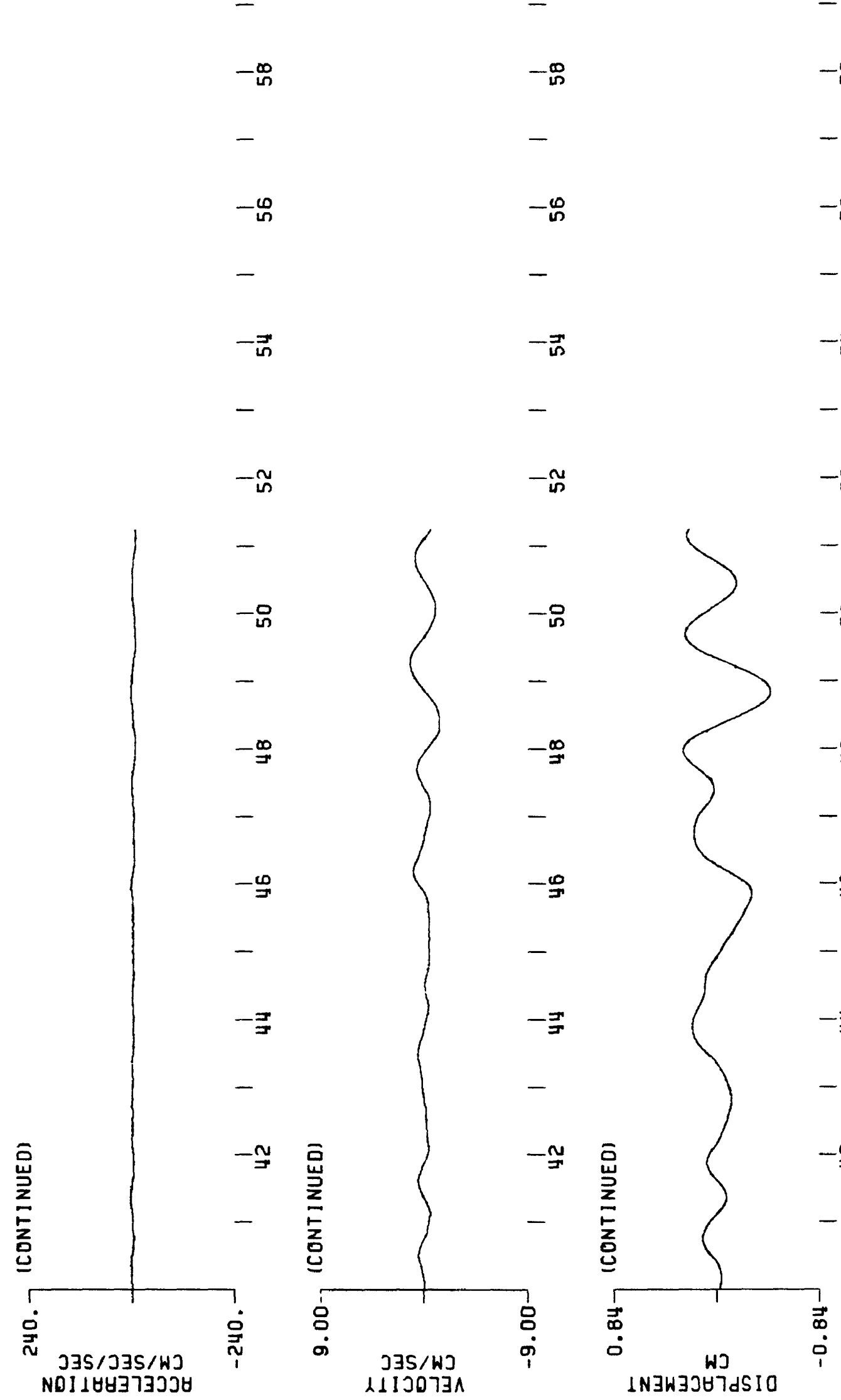

$-\infty$

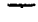

$-\frac{0}{n}$

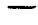

-

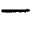

$-N$

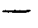

$-0$

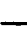

$-0$
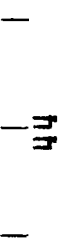

$-N$
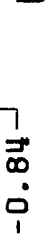
INJWJ3HTdSIO

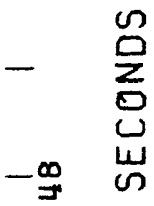




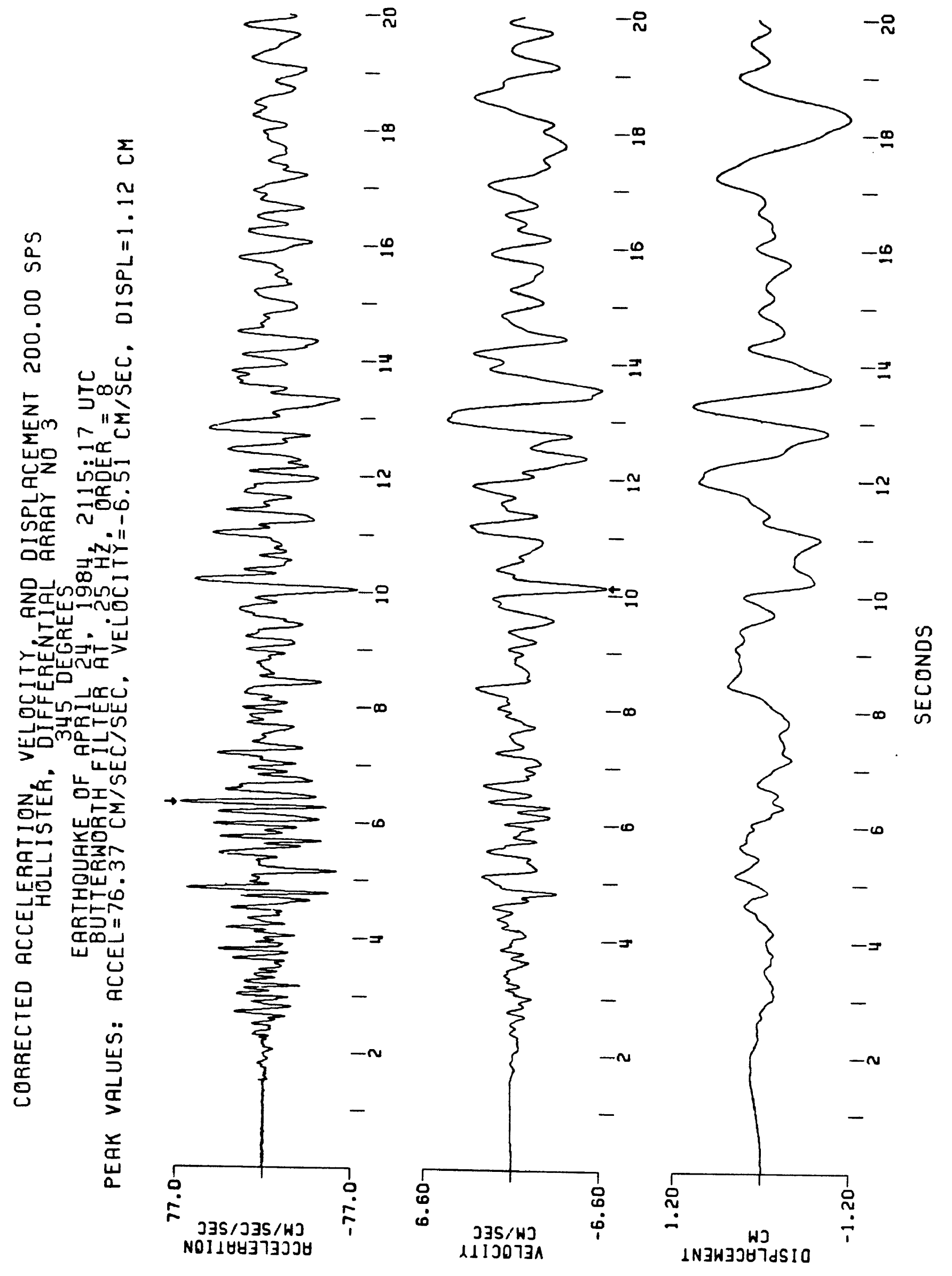




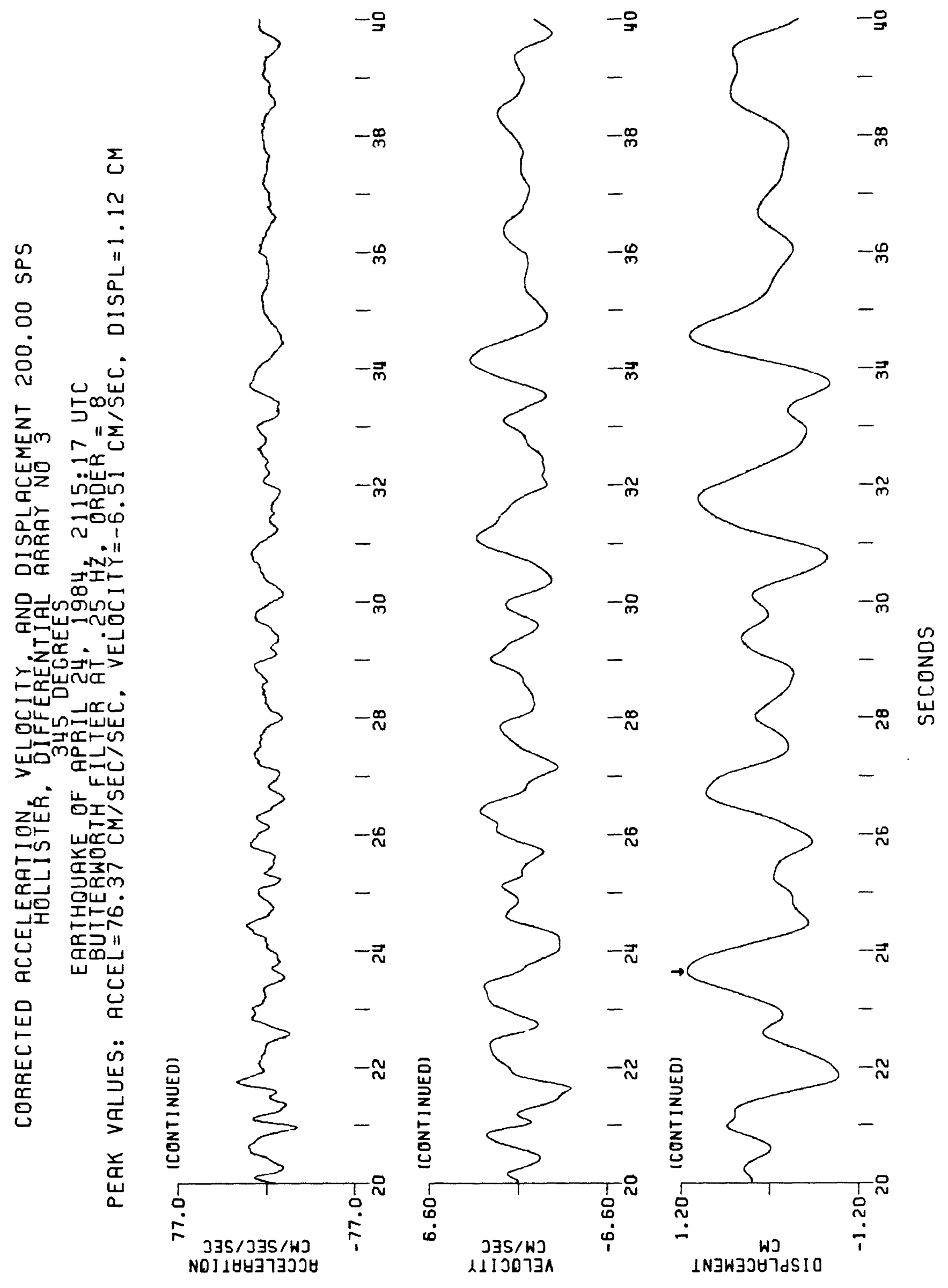




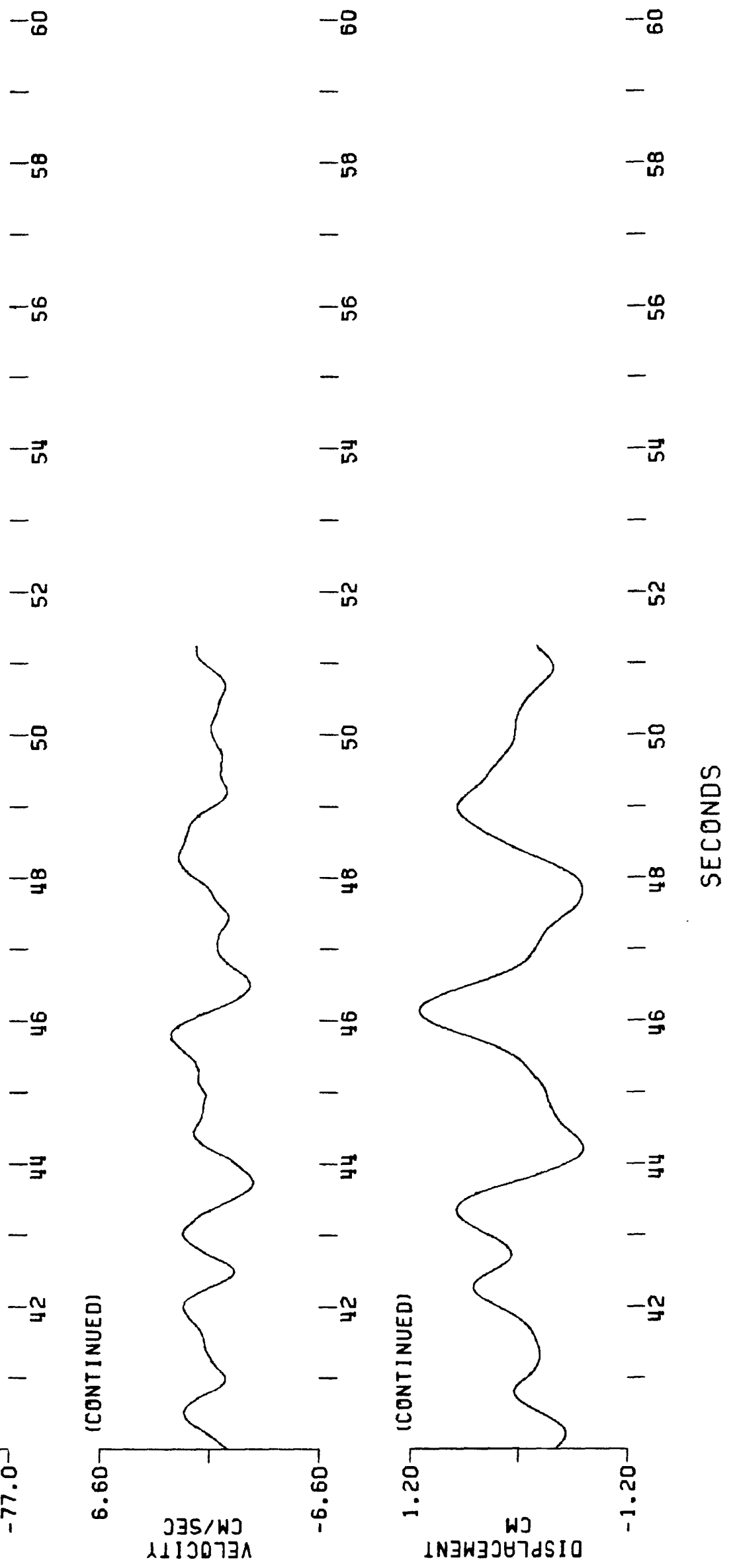




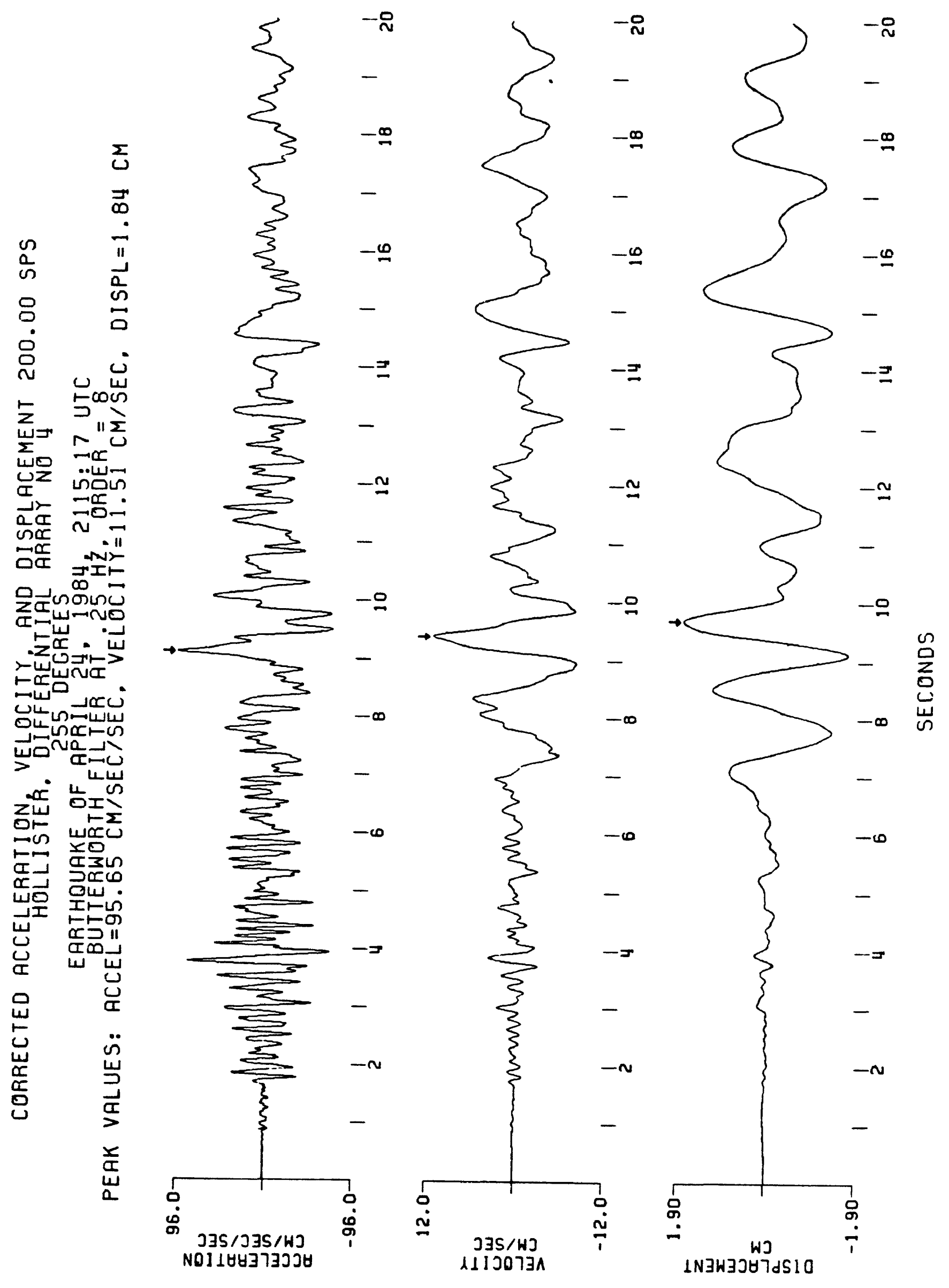




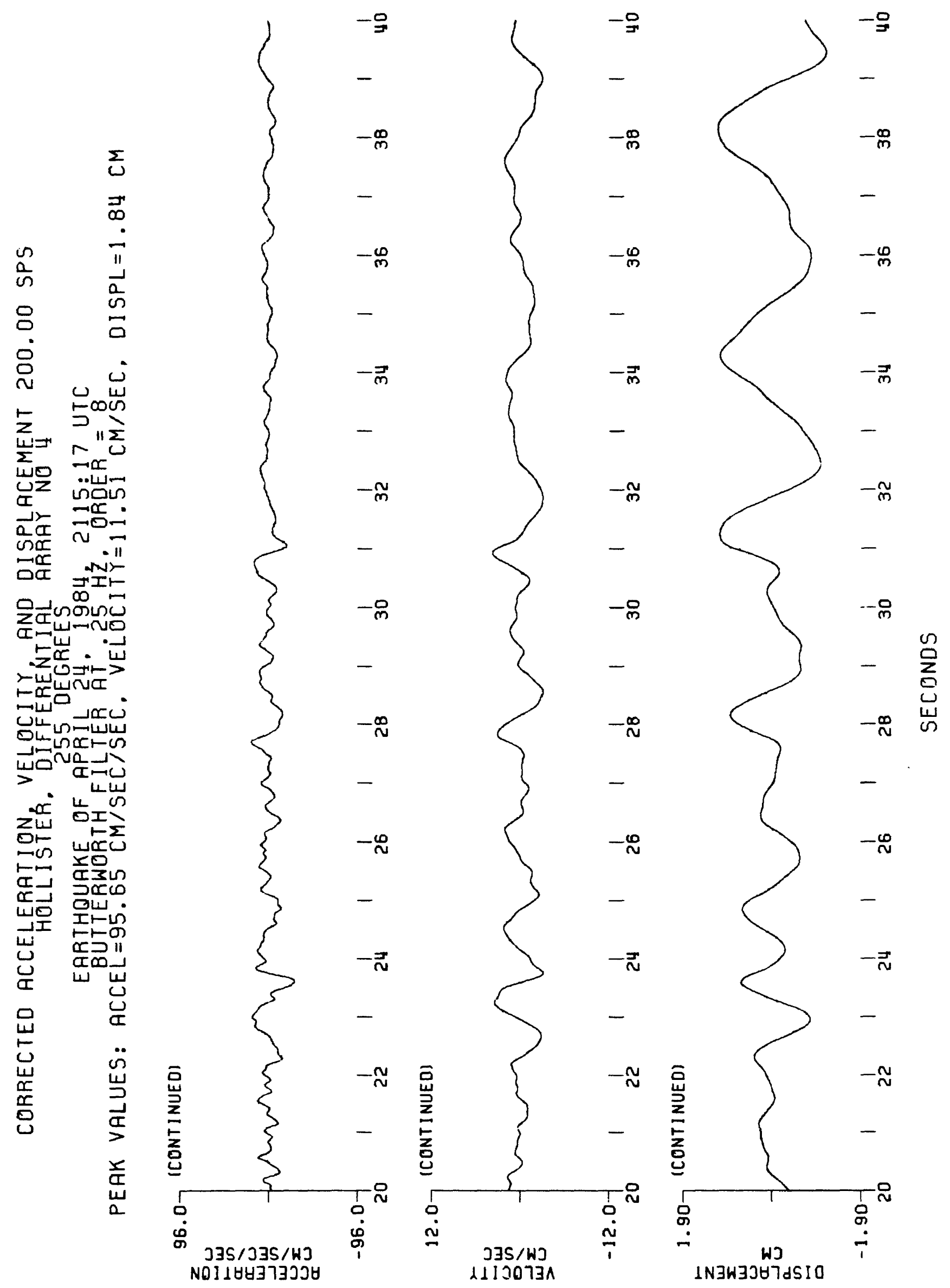




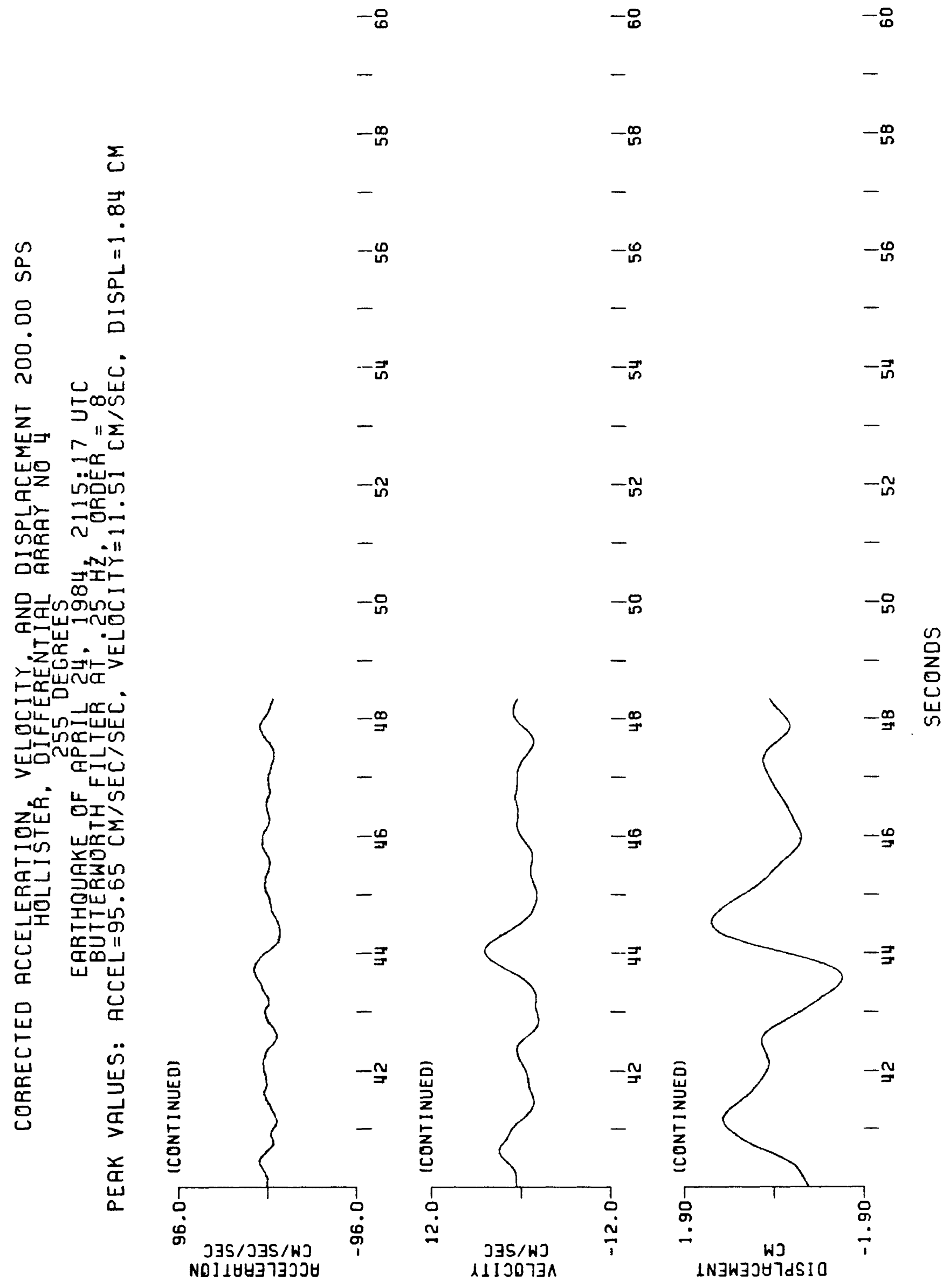




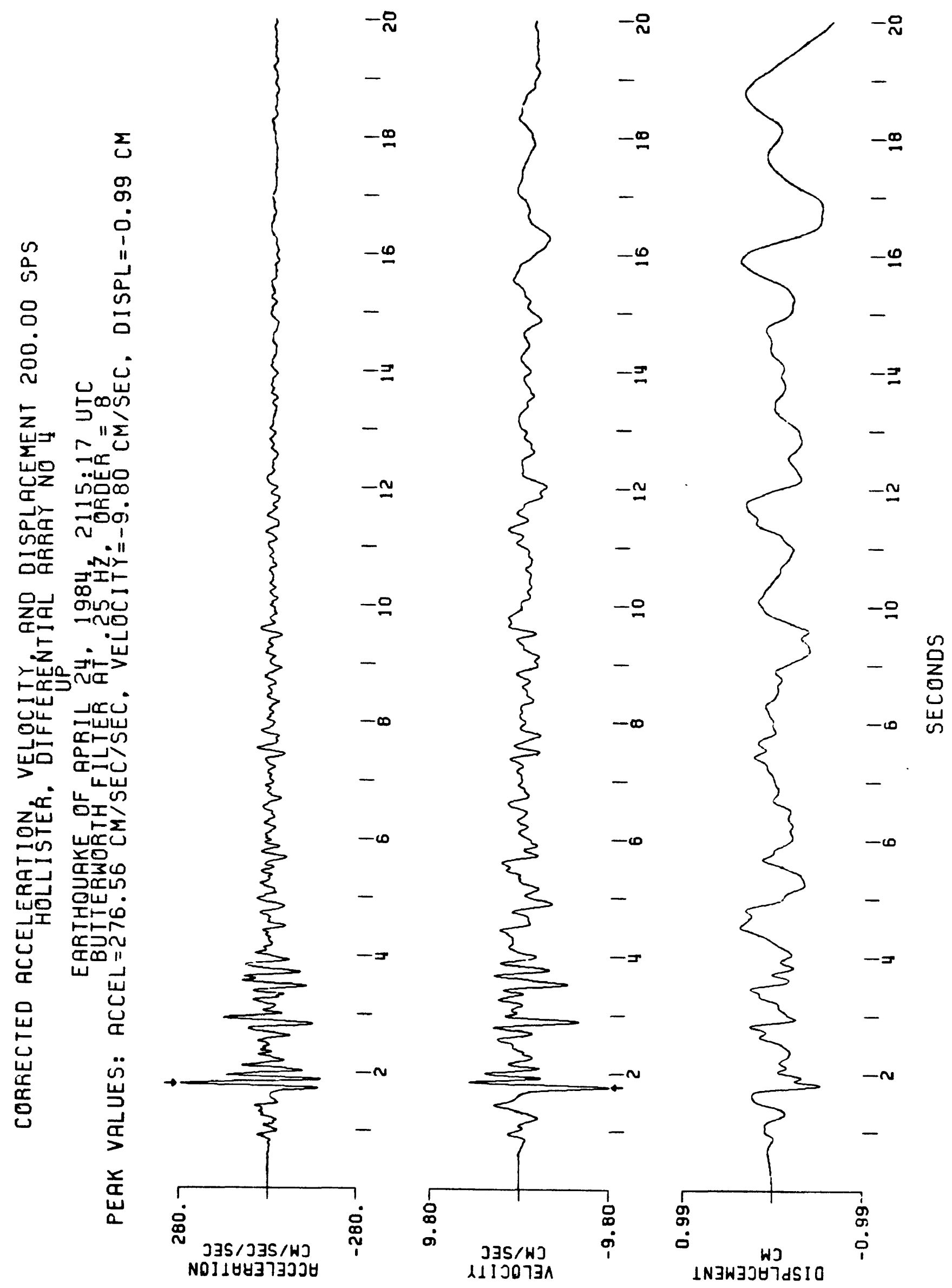




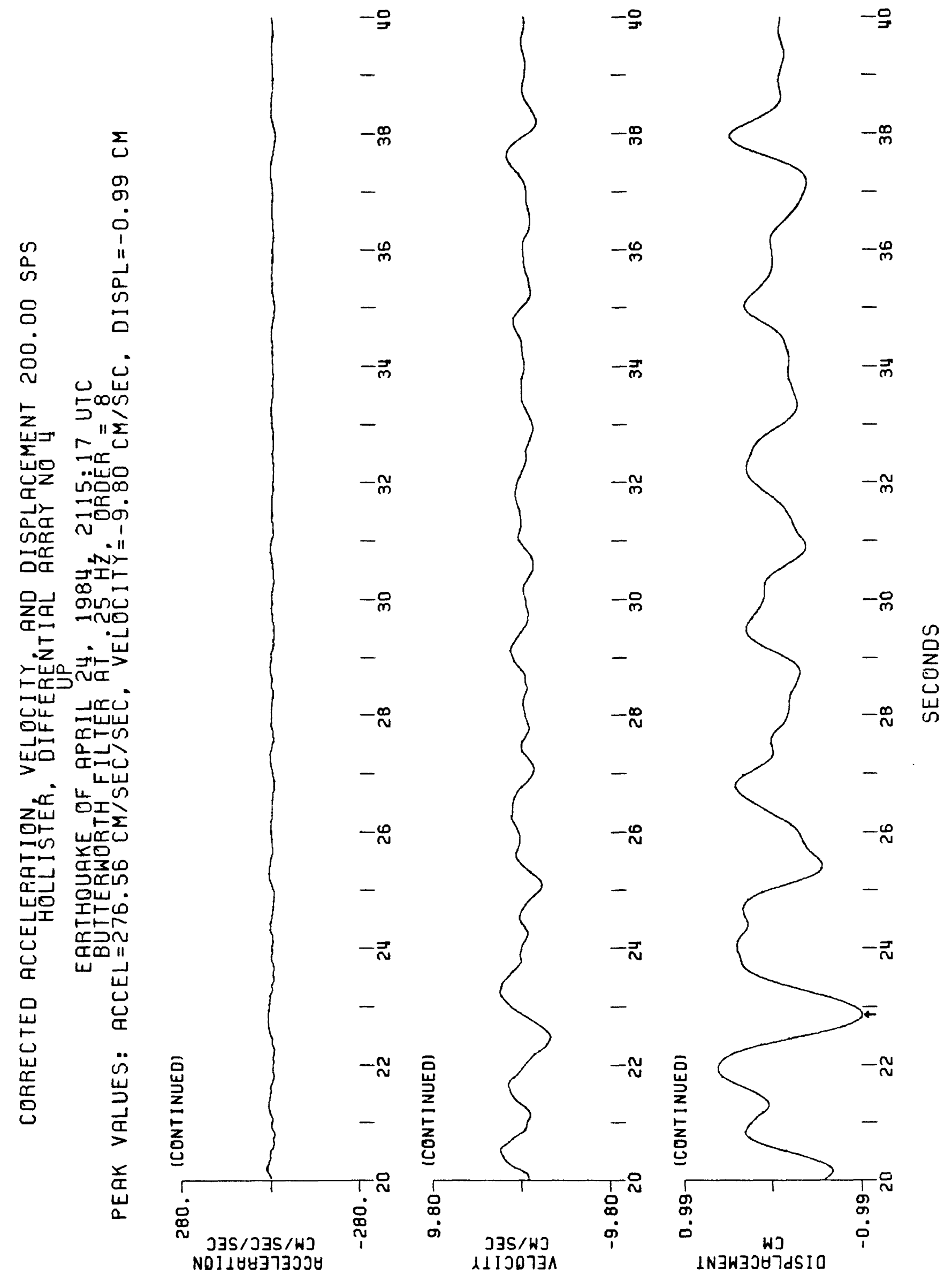




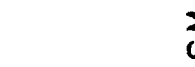

$\Sigma$

क)

$n$
0
0
0
0
0
0

in

$8 \frac{0}{0}$

•

₹

崖罗

iv口 ஈ

Uz

व $\simeq$ ㄸ.

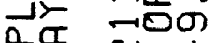

ज品 N 1

च祭 mr

㤩エ上

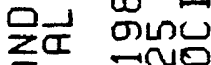

व्. ШतD

-z

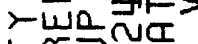

ஈாத

एu Шயய

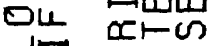

ज्ञ

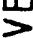

电崩

Z品

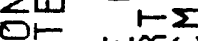

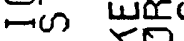

ㅍ 주

머 כ叫

믐ㄴ.

$\sim$ I느

山

凹

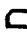

w

レ

岀

㭊

䍃

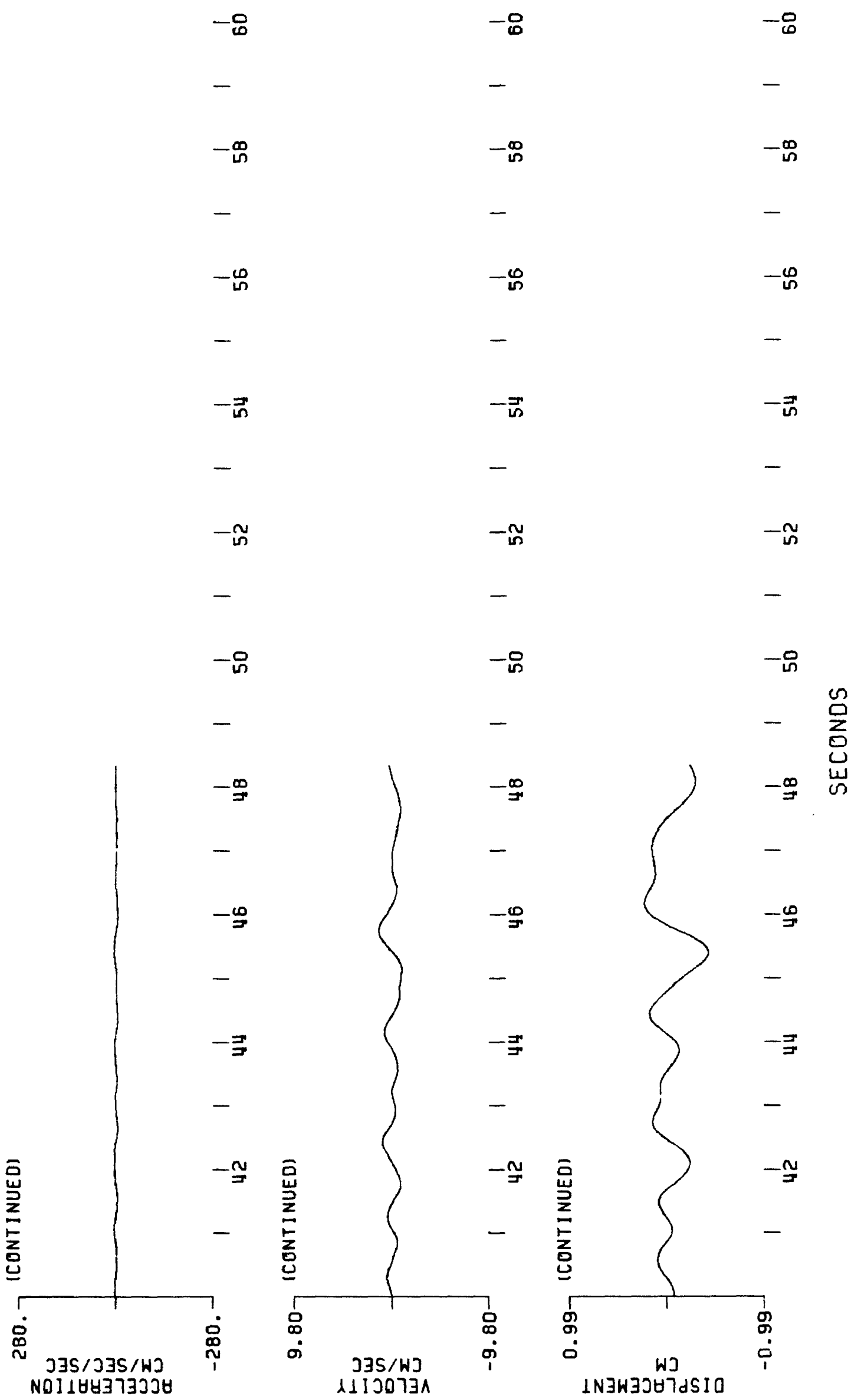




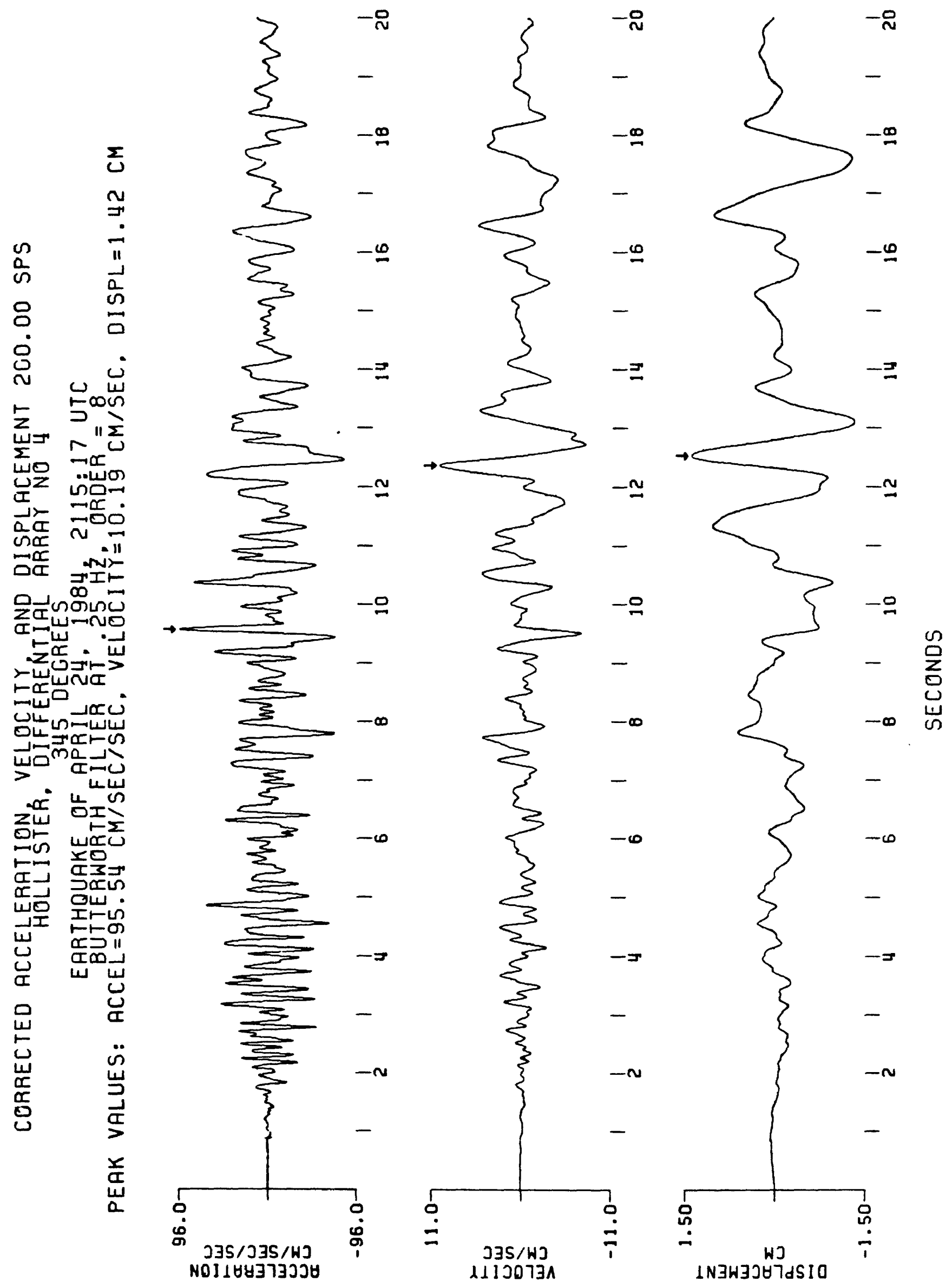




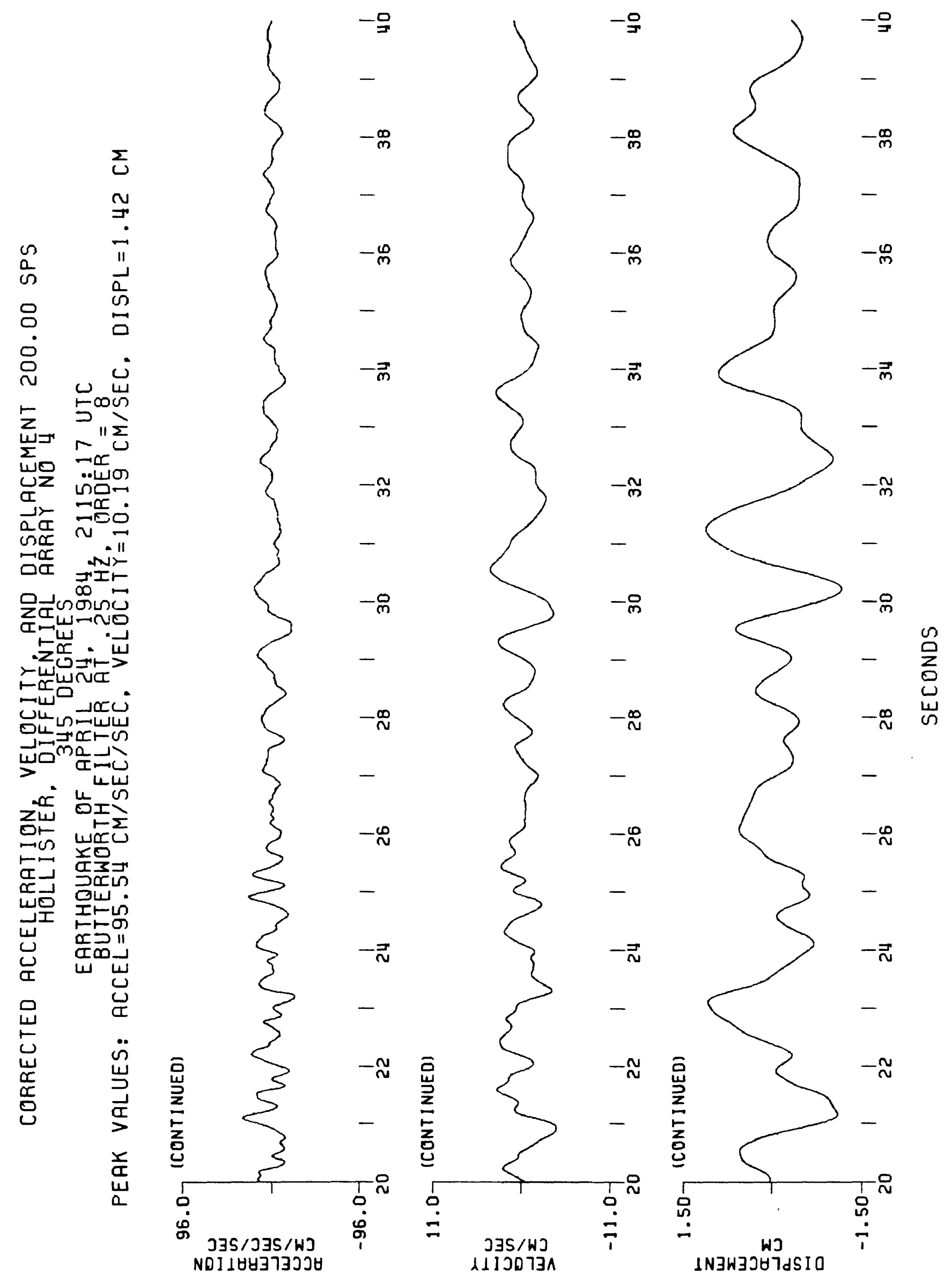




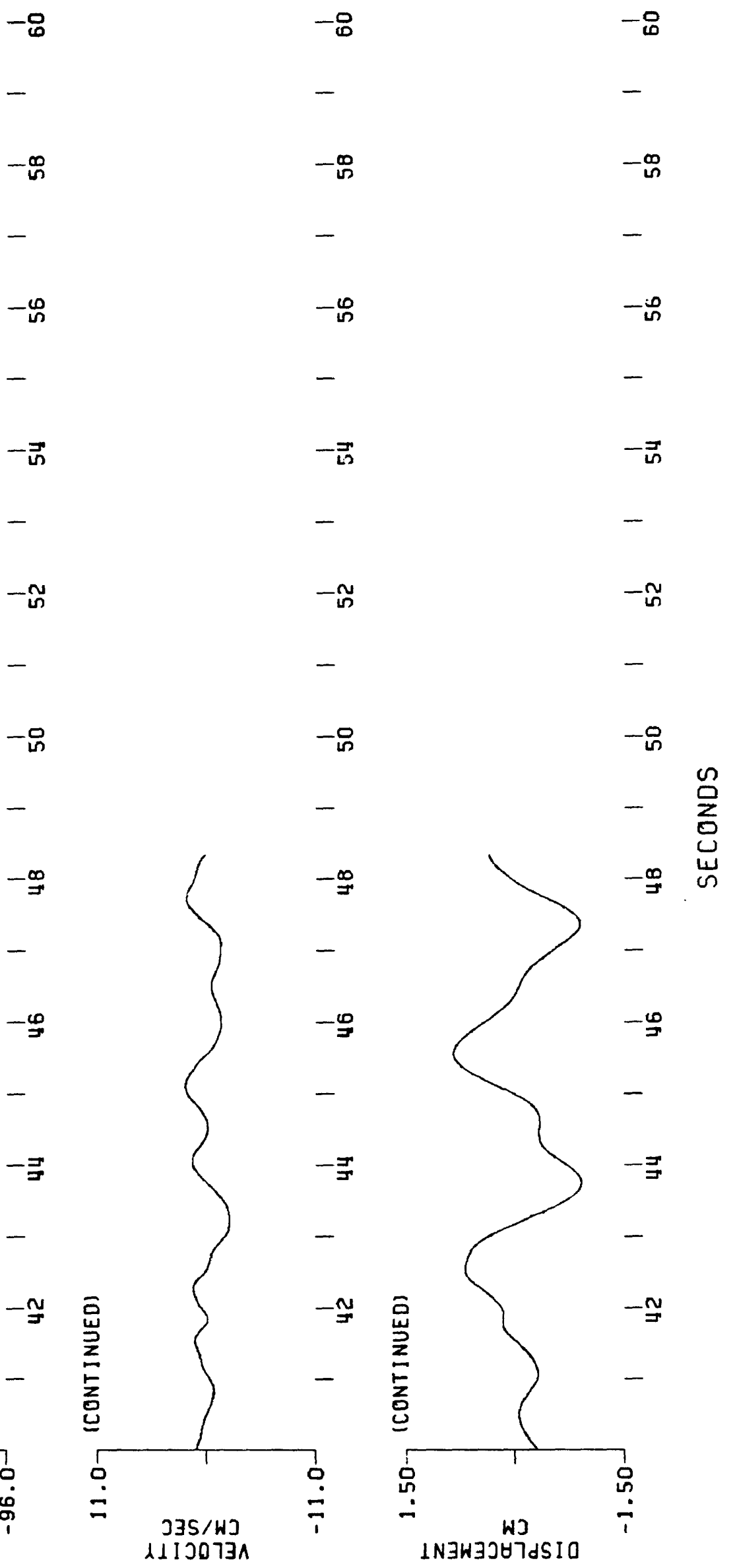




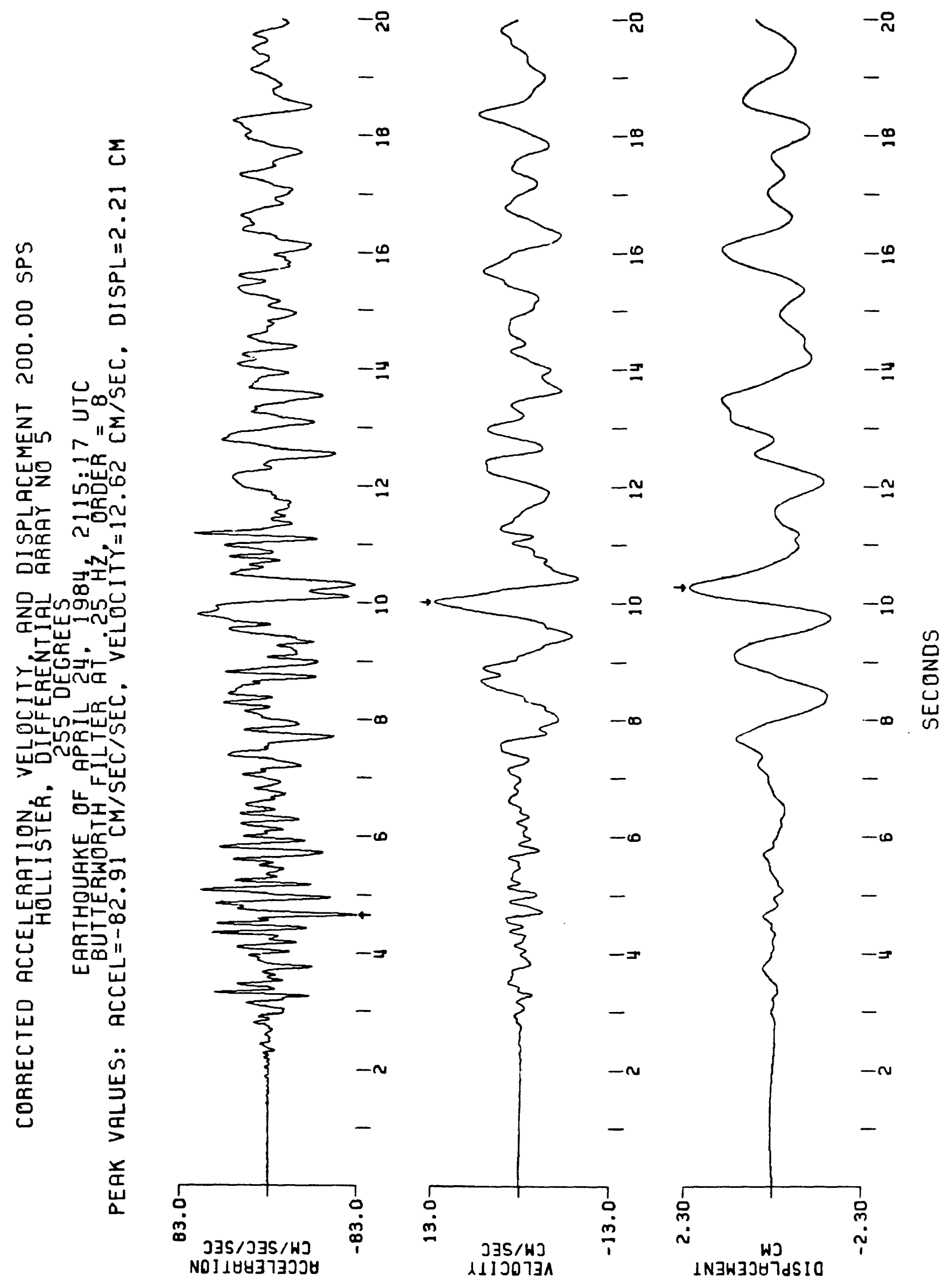




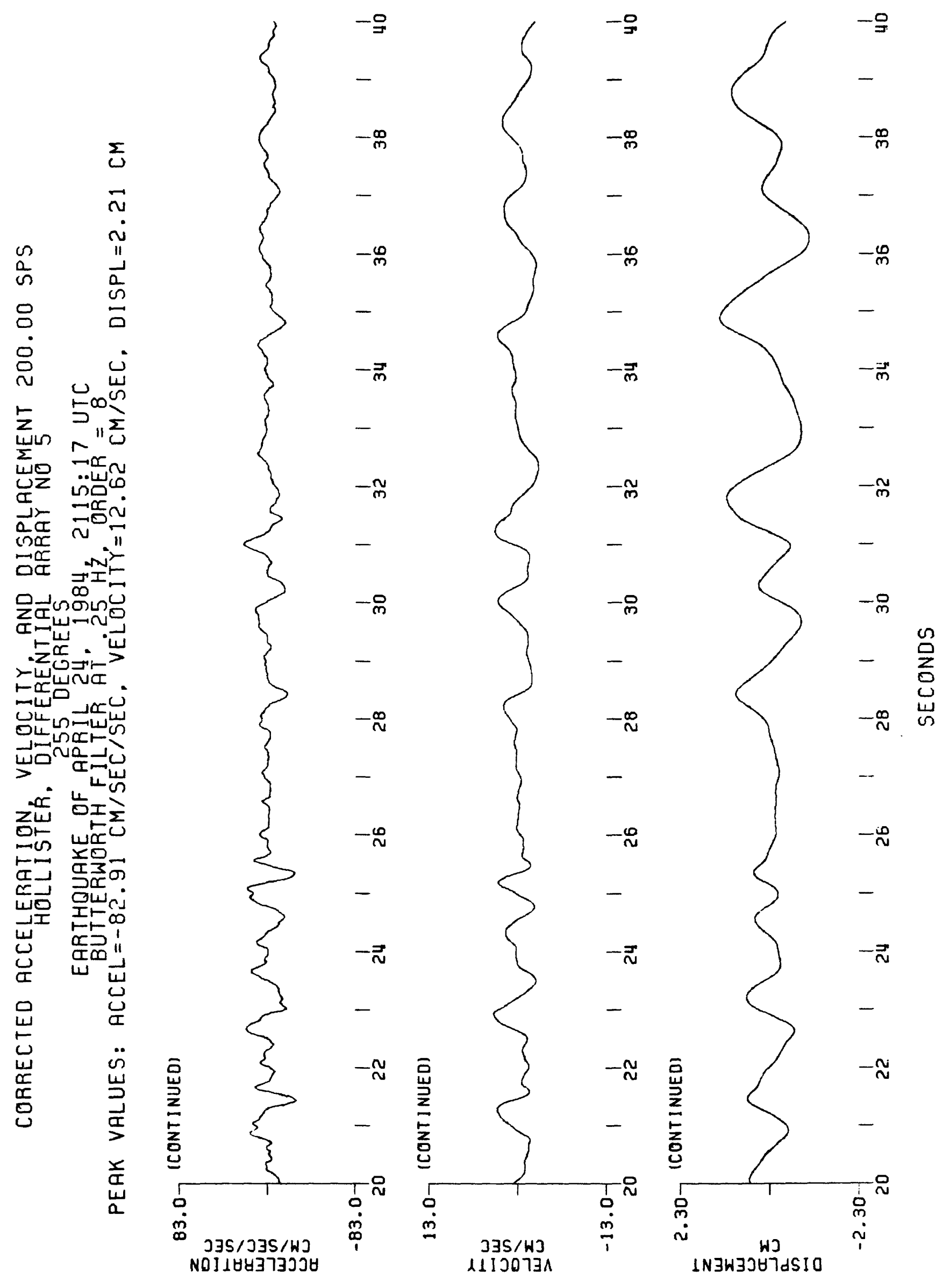


$\Sigma$

$\frac{n}{n}$

$\vec{n}$

N

음

웅

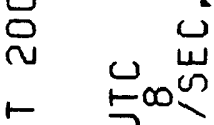

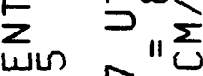
$\sum_{x=10}$

记

匹

aᄄ $\overrightarrow{0}$

जo $\sim$.

䓵 우주ำ 进山几 㟧. Z田>

Юயسता

屾

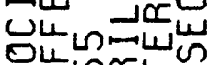

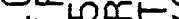

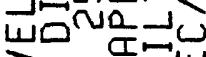

$>$. 㟧

z品告泣

of wo

№

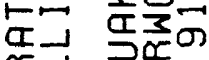

ㄹ 궁.

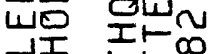

JI 15

㟧 管

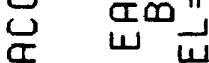

무 㫕

啋

$\underset{\sim}{\sim}$

号吉

$-\infty$

in

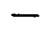

一管
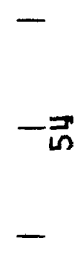

$-\tilde{ก}$

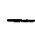

- i
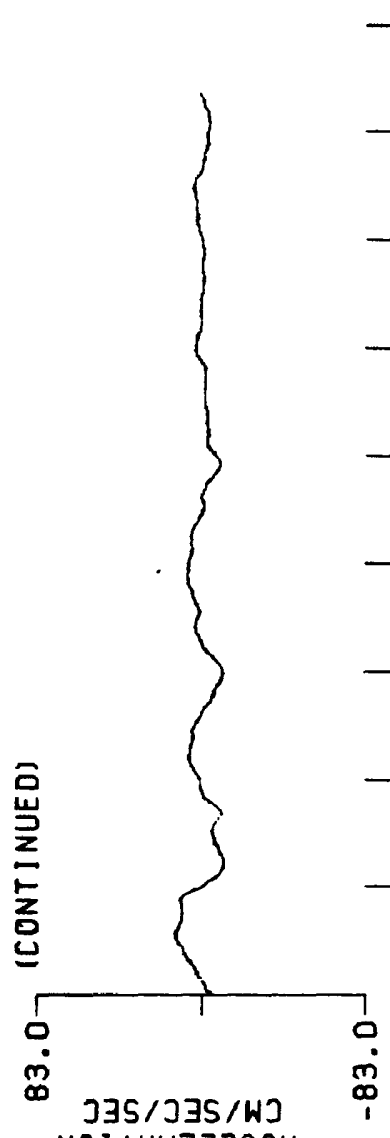

NOI $14837 \exists J 3 \forall$

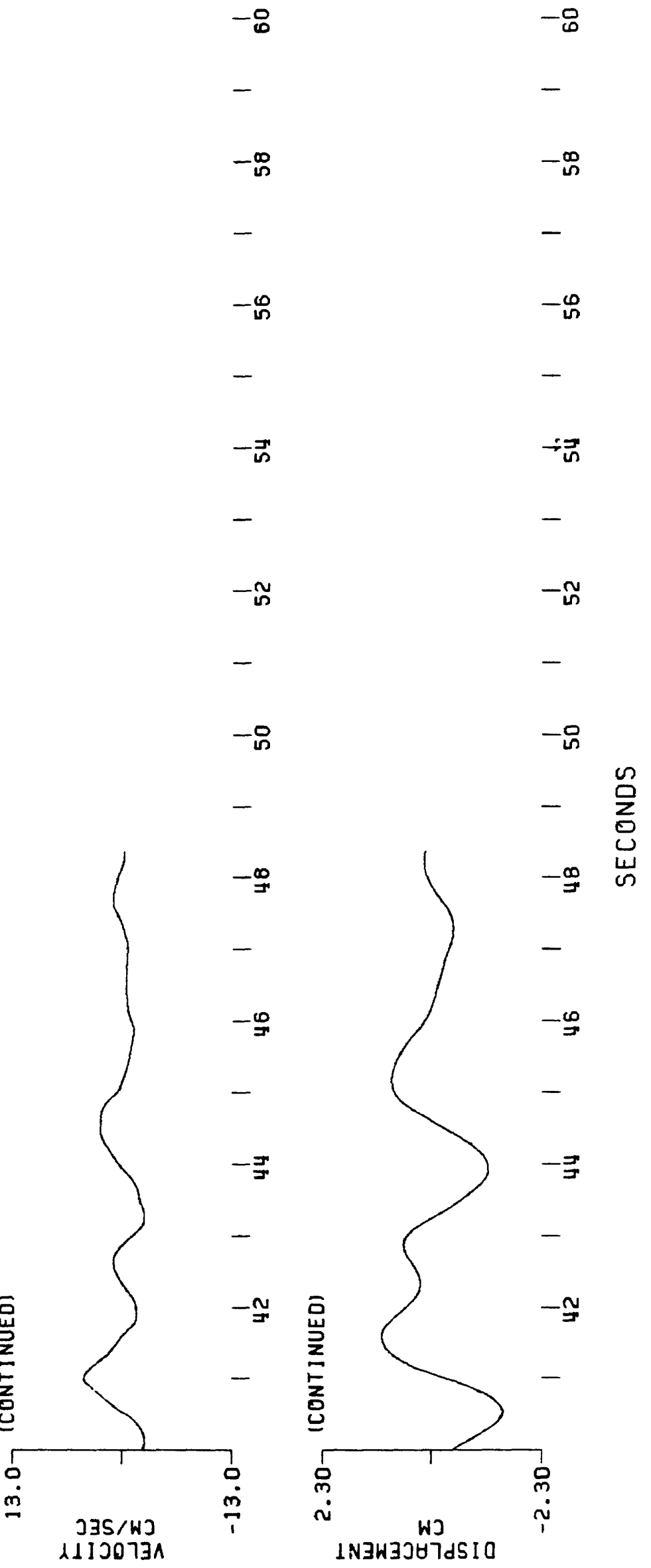




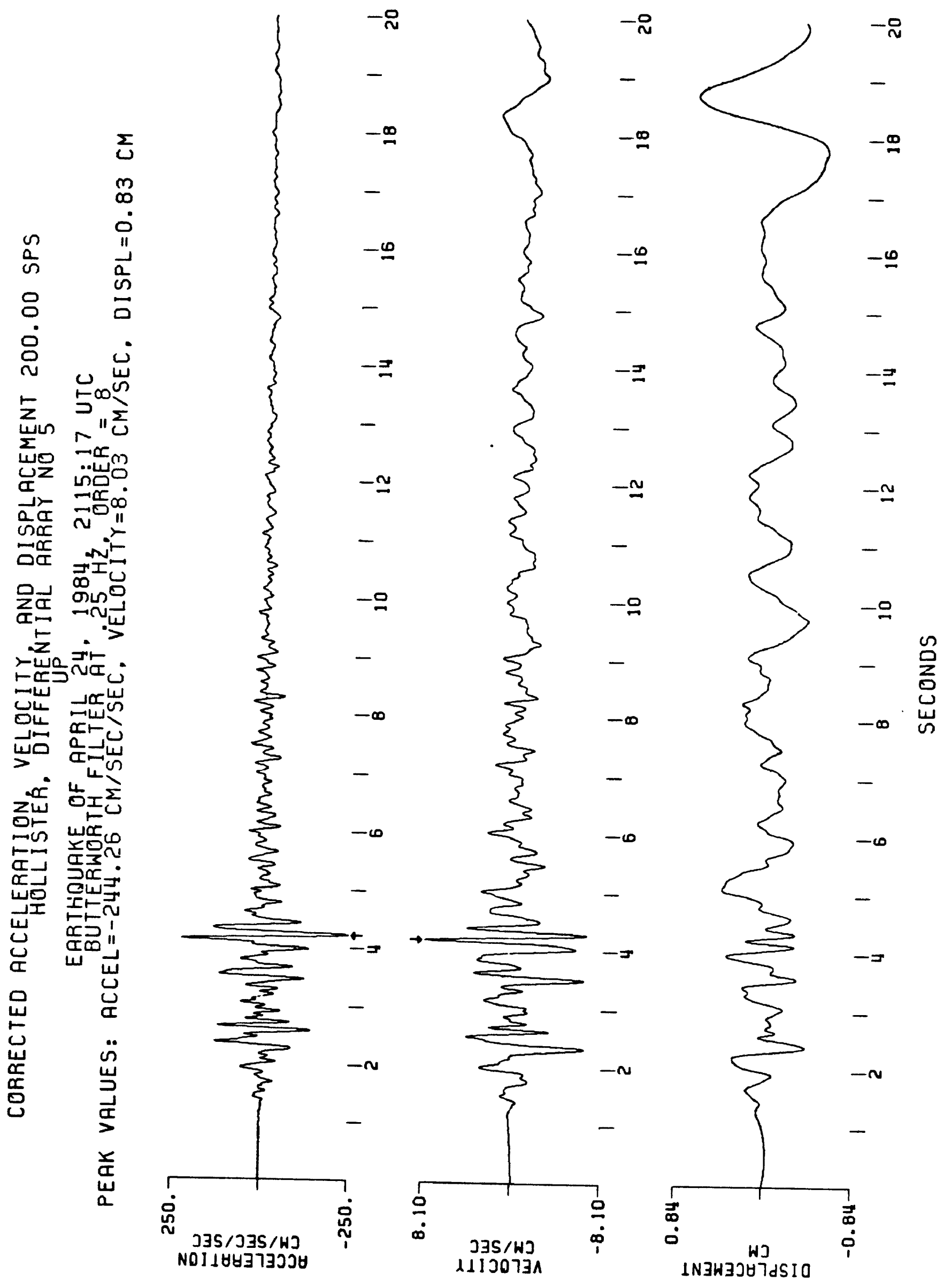




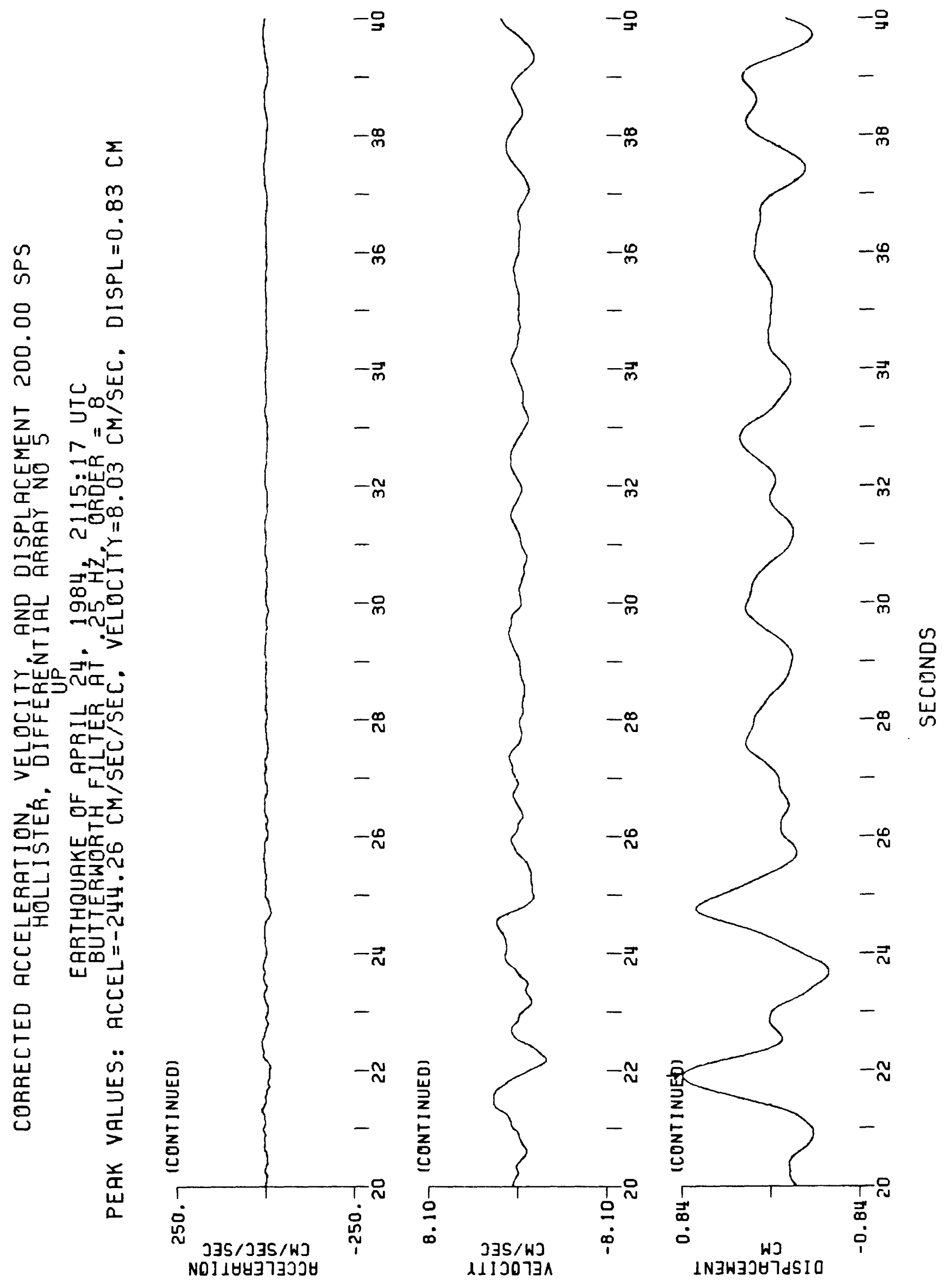


$-0$

$\Sigma$
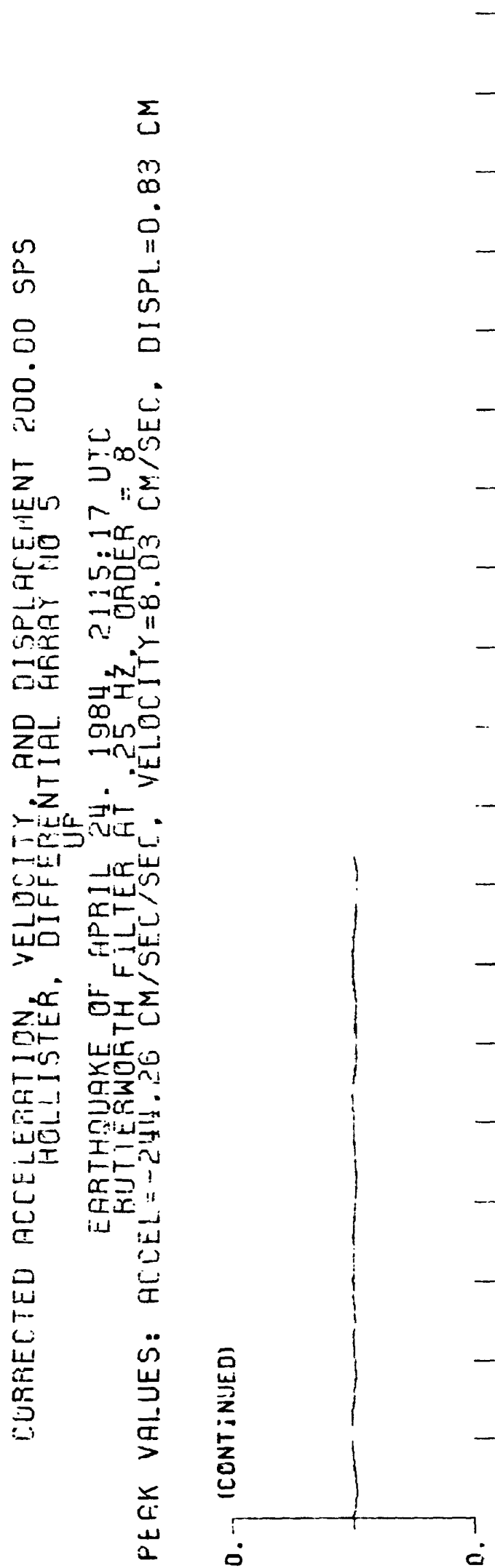

$-\infty$

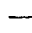

$-\frac{0}{\text { in }}$
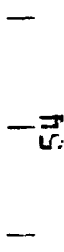

$-\tilde{n}$

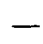

- .
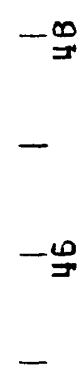

$\exists$
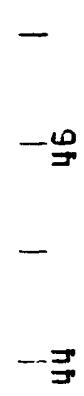

$-0$

$-0$
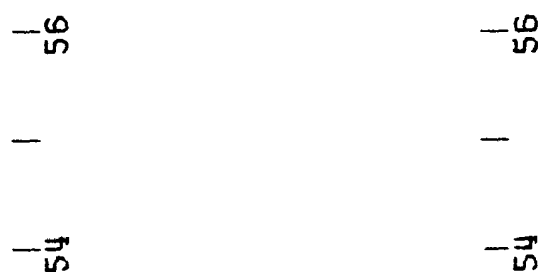

- ָี
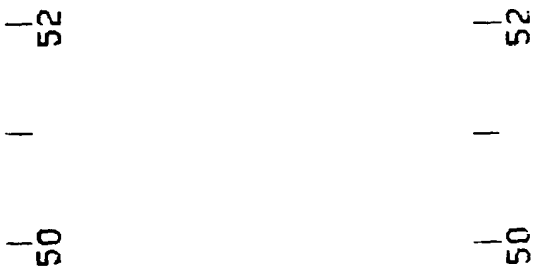

一贻
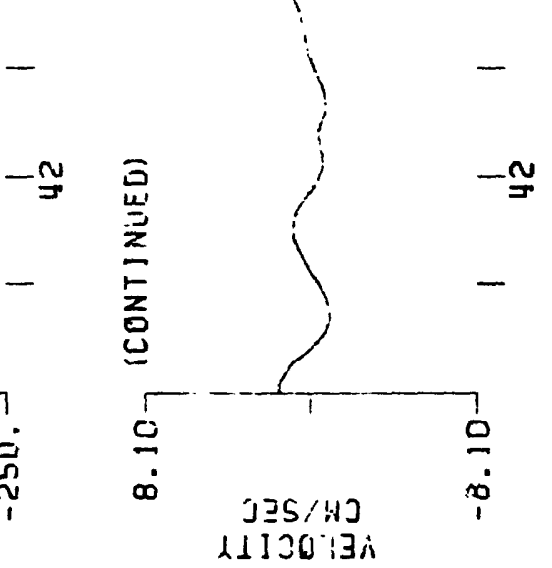
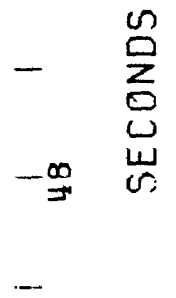

-
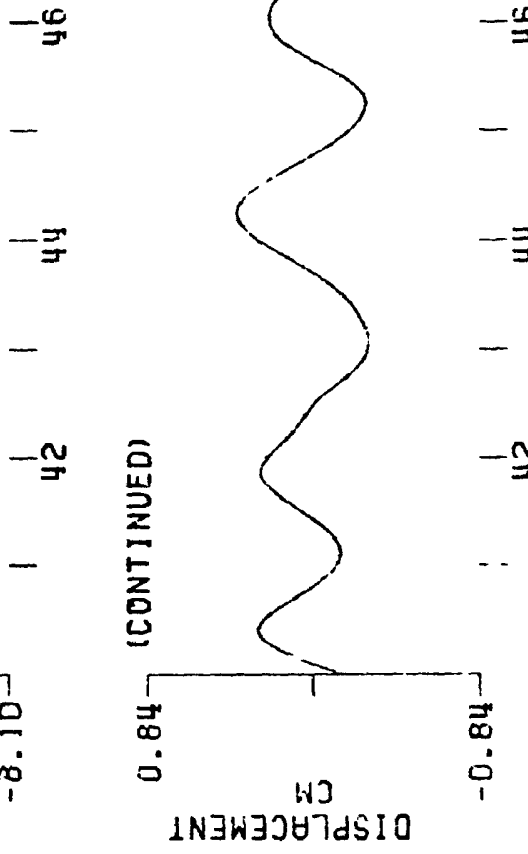


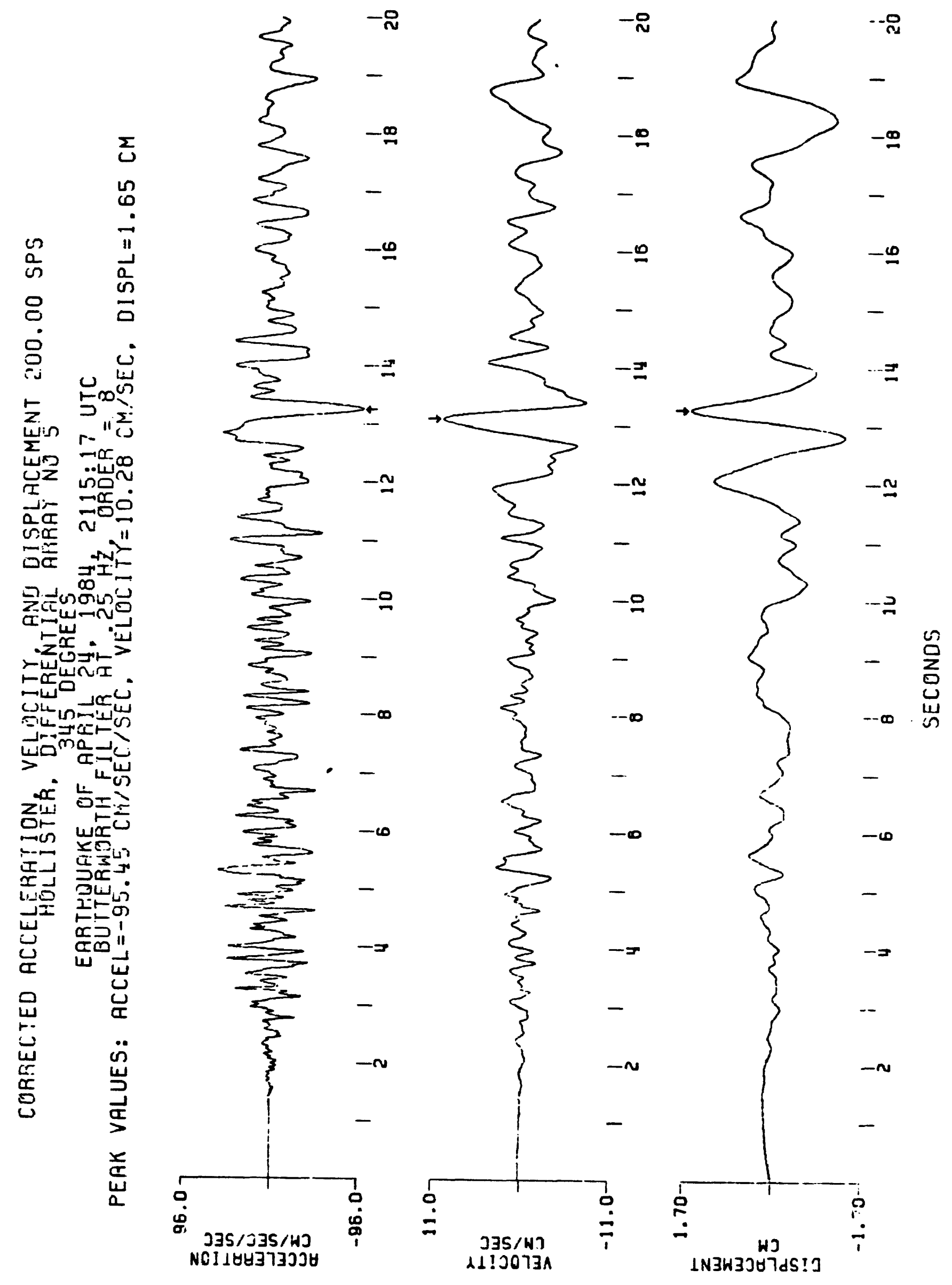




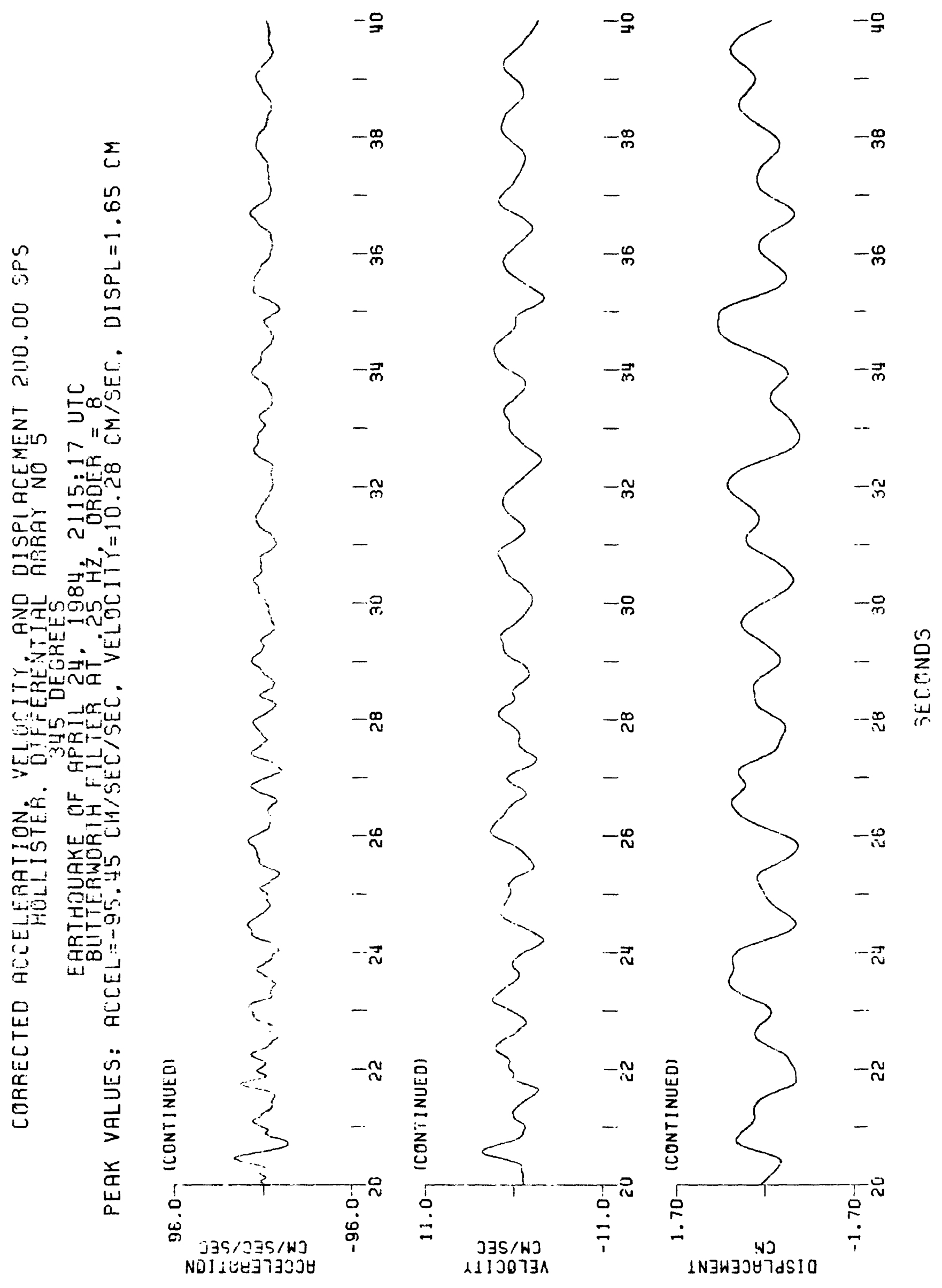


$-8$

0

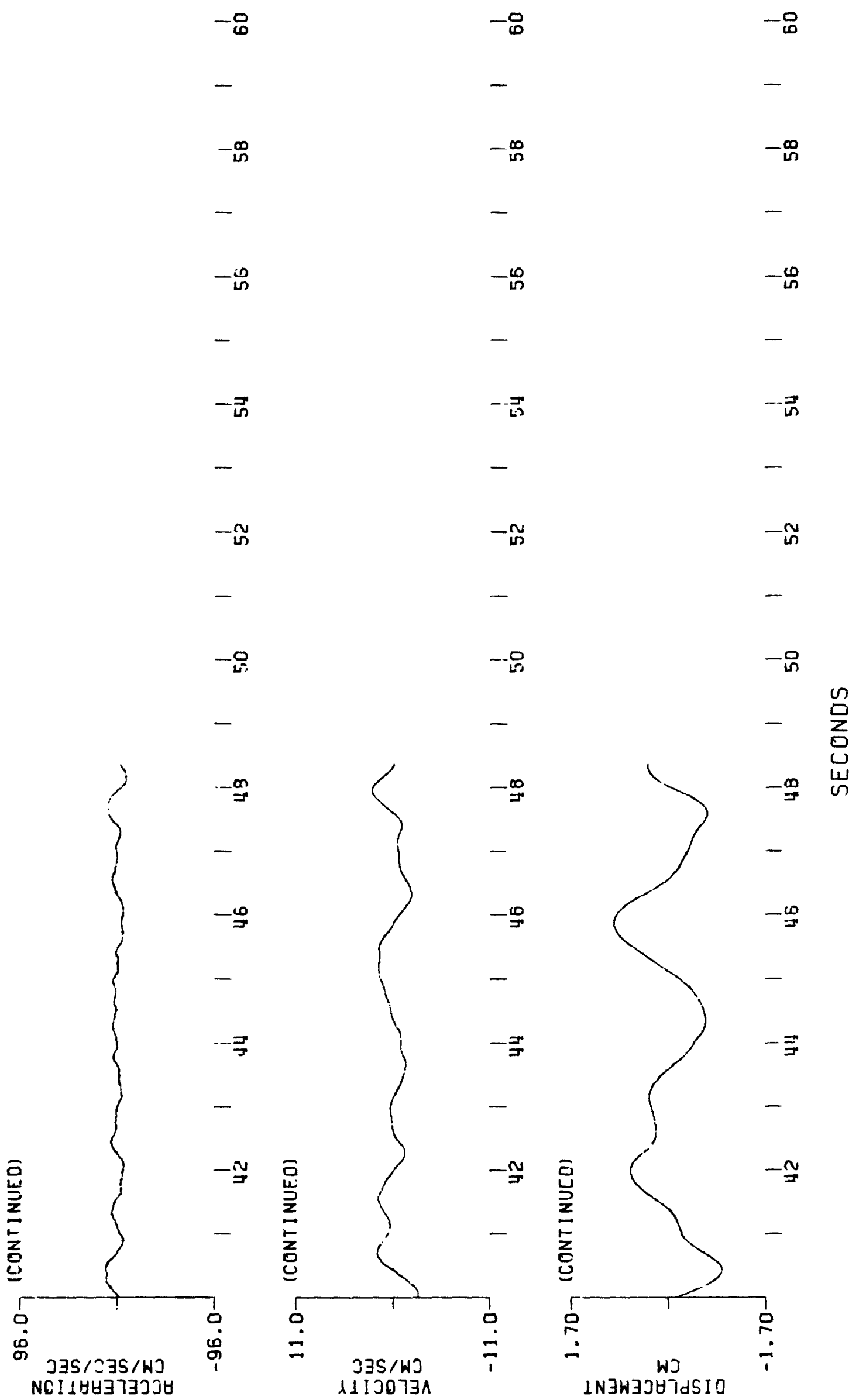

